\title{
LOCAL AND METRICAL TONE SHIFT IN NGUNI ${ }^{1}$
}

\author{
Laura J. Downing \\ University of Illinois
}

\begin{abstract}
In this paper I argue that the Nguni languages have both a metrical tone shift rule and a non-metrical (local) tone shift rule which precedes and feeds assignment of metrical prominence (accent). As Goldsmith, Peterson, and Drogo [1986] and Peterson [1989b] have argued, a metrical tone shift rule best accounts for the fact that the rightmost high tone in most words surfaces on the antepenult. Not all high tones shift to the antepenult, however; instead, they shift one syllable to the right. Earlier metrical analyses accounted for (some) of these cases by proposing rules of accent shift. The present analysis accounts for all these cases by a local tone shift rule ordered before accent assignment. This approach not only is more general and more natural than the accent shift analyses, but it also straightforwardly accounts for a number of tonal phenomena which were inadequately treated in earlier analyses.
\end{abstract}

\section{Introduction}

Zulu, Xhosa, and Ndebele are members of the Nguni sub-family of Southeastern Bantu, spoken mainly in South Africa and Zimbabwe. ${ }^{2}$ A problem of Nguni tone which has been widely discussed in the literature (see, for example, Clark [1988]; Claughton [1983]; Goldsmith, Peterson, and Drogo [1986]; Khumalo [1987]; Laughren [1984]; Louw [1971]; Peterson [1989b]; Rycroft $[1963,1979 ; 1980 \mathrm{a}, \mathrm{b} ; 1983])$ is that the rightmost high tone in a word generally

\footnotetext{
1I would like to thank a number of people for comments on this paper. First of all, I owe special thanks to James Khumalo, who not only provided hours of lively discussion on Zulu tone, but also patiently provided me with the Zululand Zulu data discussed here. Karen Peterson's very detailed comments on an earlier version of this paper [Peterson 1989a] were especially helpful in shaping the present analysis. Others whose comments helped me improve my understanding and presentation of the Nguni data were C. Bundrick, J. Goldsmith, J. Hualde, M. Kenstowicz, C. Kisseberth, N. Mutaka, R.G. Schuh, and an anonymous reviewer. Any errors of data or interpretation are, of course, my own.
} 
surfaces on the antepenultimate syllable, even though that high tone may be underlyingly associated several syllables leftward, so that, for example, underlying si-ya-wá-namathelisa 'we make them stick' sur'aces as si-ya-wa-namathélisa. Following Goldsmith, Peterson, and Drogo [1986] and Peterson [1989b], I will show in $\S 1$ that the attraction of high tones to the antepenult may be accounted for by a metrically conditioned rule which allows spread of a high tone to the antepenult once that syllable has been assigned metrical prominence in a word.

A problem with these earlier metrical accounts of Nguni tone is that they do not adequately account for the fact that high tones originally associated with the antepenult generally shift one syllable rightward, namely to the penultimate syllable, so that, for example, underlying u-ya-bá-hleka 'you laugh at them' surfaces as u-ya-ba-hléka. In $\S 2$, I account for antepenult to penult tone shift by arguing that Nguni has not only a metrical tone shift rule, but also a rule of local tone shift which spreads a high tone one syllable to the right; this rule applies before metrical structure is assigned. ${ }^{3}$ Although this analysis conflicts with other models of the interaction of tone and accent, e.g. Goldsmith [1982] and Sietsema [1989] which postulate that all metrical, i.e. accentual, rules should precede all local tone rules, I will show that local tone rules must precede metrical rules not only in Nguni, but also in the tonal systems of other Bantu languages. Further, the rule of local tone shift will be argued to provide both a more general and a more natural account of the Nguni data than the accent shift rules of previous metrical analyses.

Finally, in $\S 3, I$ discuss some apparent exceptions to local tone shift and show that most have a straightforward phonological explanation. In particular, I argue that one set of synchronic exceptions can be accounted for, if local tone shift applies to these forms before an underlying, historically-motivated vowel length contrast is neutralized.

\footnotetext{
2 The Zulu data discussed in this paper comes from my work with James Khumalo, a native speaker of the Zululand Zulu dialect. Only Zululand Zulu data is cited in the paper; the few references to Natal Zulu are based on data presented in Cope [1970] and Rycroft [1963]. The Xhosa verb data is taken mainly from Claughton [1983]. Xhosa noun data and additional verb data come from Westphal and Notschweleka [1967], supplemented by Lanham [1958], Louw [1971], and Westphal [1951]. The Ndebele data comes from two papers by Rycroft [1980b] and [1983].

3 Zulu and Ndebele have another well-known rule which has the effect of shifting high tones rightward in some contexts, namely, depressor-consonant induced shift. Since depressor shift applies after local and metrical shift, and depressor consonants do not seem to block either rule, I will not discuss this issue in the present paper. I refer the interested reader to Khumalo [1987], Lieber [1987], Laughren [1984], Peterson [1989b], and Rycroft [1979, 1983] for relevant data and discussion. The effect of depressor consonants in Xhosa is described briefly in Louw [1971] and Westphal and Notshweleka [1967].
} 


\section{Antepenult Shift}

1.1. Preliminaries. The first point $I$ will discuss is that of high tone shift to the antepenult. But before introducing an analysis of this problem, some background on Nguni morphology and tone is necessary.

Nouns and verbs in Nguni are composed of root morphemes to which suffixes and prefixes may be added. I shall refer to the noun or verb root followed by all suffixes (including the final vowel) as the "stem". Derivational suffixes cited in this paper are, for nouns, the diminutive -(y)ana and, for verbs, the so-called "extensions", which include the causative -is-, the benefactive -el-, and the reciprocal -an-. Prefixes for nouns are the class agreement prefix (in the "short" form) and, in the "long" form, an additional pre-prefix. The infinitive also has these nominal prefixes. Verb prefixes in the data cited include subject agreement prefixes (SP), tense-aspect markers (TM), and object prefixes (OP), which occur in that order preceding the verb stem.

Nguni noun and verb stems contrast in that some have high tones and some are entirely low-toned. This contrast is illustrated in the "short" forms of the Nguni infinitives cited below:

(1) "Short" form of the infinitive ( $k u$ - is the infinitive prefix; this form would appear in phrases like akúkho ... 'there is no__' $)^{4}$ :

\section{A. High-toned verbs}

$\underline{\text { Zulu }}$

(a) ku-phạkámisa

(b) ku-thengisélana

Xhosa

(c) ku-bónísisa

(d) ku-nyịnyíthékisa

Ndebele

(e) ku-le thísana 'to lift up'

'to sell to (recip.)'

'to show clearly'

'to make slippery'

'to help bring (recip.)'

\footnotetext{
4 In this and all following data, hyphens separate morphemes, and underlyingly high-toned vowels are underlined. In the Xhosa data, all vowels between (and including) the underlyingly high-toned vowel and the target of tone spread are marked with a high tone, but, according to Claughton [1983], only the rightmost high-toned vowel is obligatorily realized with a high tone; the others are only optionally high-toned. If one of these vowels is realized with a high tone, however, then all rightward vowels must also be high.
} 


\section{B. Low-toned verbs}

$\underline{\text { Zulu }}$

(f) ku-khethisa

(g) ku-hlekisana

'to help choose'

'to amuse (recip.)'

Xhosa

(h) ku-shukumisa

'to shake'

(i) ku-namathelisa

'to cement'

Ndebele

(j) ku limisisa

'to plow intensively'

Since low tones do not play any role in most of Nguni tonology, I assume an underspecified representation for Nguni in which only high tones appear underlyingly and low tones are filled in by a default rule applying late in the phonology. This type of underspecified approach has been previously argued for in Nguni (see Clark [1988] and Khumalo [1987] on Zulu, Goldsmith, Peterson, and Drogo [1986] on Xhosa, and Peterson [1989b] on Ndebele) as well as in a number of other Bantu languages, such as Digo [Kisseberth 1984], ChiZigula [Kenstowicz and Kisseberth 1990], Haya [Hyman and Byarushengo 1984], LuGanda [Stevick 1969], Shona [Myers 1987], the SeSotho/SeTswana group (ongoing research under C. Kisseberth at the University of Illinois), and Tonga [Pulleyblank 1986], to name only a few. The argument in all these cases for eliminating low tones from the underlying representation is the one just mentioned, namely, that low tones are neither the target nor the context of most of the tone rules of these languages. (Following traditional terminology, I will continue to refer to the underlyingly toneless stems as "low-toned" in this paper, however.)

1.2. Evidence for antepenultimate prominence in Nguni. To turn to the problem of antepenult shift, if we look again at the tone pattern of the stems in (1), we notice that the high tone surfaces on the antepenult of these stems even though it is often originally associated several syllables leftward. I will assume in this paper that the high tone of most morphemes is unlinked underlyingly, and associated early in the phonology to the first syllable of the morpheme by the Universal Association Convention (UAC), defined in (2):

(2) Universal Association Convention (following Pulleyblank [1986])

Map a sequence of tones onto a sequence of tone-bearing units (TBU) one-toone from left to right. 
When the stem-initial syllable is in pre-antepenultimate position, as in (1), its high tone shifts to the antepenult. If high-toned prefixes are added to low-toned stems, we likewise find that pre-antepenultimate high tones shift to the antepenult. The class agreement preprefixes of nouns and infinitives, for example, have a high tone, which shifts rightwards to the antepenult preceding low stems, as illustrated by the data below:

(3) "Long" form of low-toned infinitives (with preprefix, ú-; structure of the words is preprefix-prefix-stem)

$\underline{\text { Zulu }}$
(a) ú-kú-bala
'to count'
(b) $\underline{u}-k u ́-h l e k a$
'to laugh'
(c) u-ku-hlékisa
'to amuse'
(d) un-ku-hlabélela
'to sing'
(e) $\underline{u}$-ku-hlekísana
'to amuse (recip.)'
(f) $\underline{u}$-ku-namathélisa
'to make stick'

Xhosa
(g) úu-kú-bala
'to count'
(h) ú-kú-bálisa
'to recount'
(i) u-kú-shúkúmisa
'to shake'
(j) úi-kú-námáthélisa
'to cement'

Ndebele
(k) úu-kú-khetha
'to choose'
(1) ú-kú-khéthisa
'to help choose'
(m) ú-kú-límísisa
'to plow intensively'

(4) "Long" form of low-toned nouns (all class agreement preprefixes have a high tone; the structure of Nguni nouns is identical to infinitives)

$\underline{\text { Zulu }}$
(a) a-bá-ntw-ana
'child'
(b) a-ba-ntw-ány-ana
'small child' 
Xhosa and Ndebele
(c) á -bá-ntw-ana
'child'
(d) á-bá-ntw-ány-ana
'small child'

(Note that in the Ndebele data, if the high tone is originally associated with a word-initial syllable, not only is the antepenult high-toned, but also the initial syllable and all intervening syllables remain high-toned.)

The same alternations occur when other high-toned prefixes are added to low stems. For example, third person subject prefixes are high-toned, as shown by the paradigm in (5):

(5) Indicative tense, paradigm of low verb, u-kú-ñiba 'to retreat' (verb has form: SP-TM-Stem; this example is from Zulu, but equivalent paradigms are found in Xhosa and Ndebele)

$\begin{array}{llll}\text { ngi-ya-ñiba } & \text { 'I retreat' } & \text { si-ya-ñiba } & \text { 'we retreat' } \\ \text { u-ya-ñiba } & \text { 'you retreat' } & \text { ni-ya-ñiba } & \text { 'you (pl.) retreat' } \\ \text { u-yá-ñiba } & \text { 'he retreats' } & \text { ba-yá-ñiba } & \text { 'they retreat' }\end{array}$

The data in (6) show that the high tone of the subject prefix shifts to the antepenult if it is underlyingly on a pre-antepenultimate syllable:

(6) Low verb stem with high-toned subject prefix, Indicative tense (verb has form: SP-TM-Stem):

$\underline{\text { Zulu }}$
(a) un-yá-bala
's/he counts'
(b) u-yá-hleka
's/he laughs'
(c) ba-ya-límisa
'they help plow'
(d) u-ya-hlékisa
's/he amuses'
(e) u-ya-shukúmisa
's/he shakes'
(f) un-ya-namathélisa
's/he makes stick'

$\underline{\text { Xhosa [Claughton 1983] }}$
(g) lí-yá-bala
's/he counts'
(h) lí-yá-bálisa
's/he recounts'
(i) lí-yá-shúkúmisa
's/he shakes' 
(j) lí-yá-námáthélisa 's/he cements'

Ndebele [Rycroft 1983]
(k) ú-yá-khetha
's/he chooses'
(1) ú-yá-khéthisa
's/he helps choose'
(m) ú -yá-límísisa
's/he plows intensively'

Object prefixes also have a high tone, which shifts to the antepenult from pre-antepenultimate syllables, as shown in (7):

(7) Low verb stem with a low-toned subject prefix and a high-toned object prefix, Indicative tense (verb has form: SP-TM-OP-stem):

$\underline{\text { Zulu }}$
(a) si-ya-m-límisa
'we help him plow'
(b) u-ya-ngị-hlékisa
'you amuse me'
(c) si-ya-wa--shukúmisa
'we shake them'
(d) si-ya-wa-namathélisa
'we make them stick'

Xhosa [Claughton 1983]

(e) ni-ya-wä-bálisa

'I recount to them'

(f) ni-ya-wạ-shúkúmisa

'I shake them'

(g) ni-ya-wa-námáthélisa

'I cement them'

Ndebele [Rycroft 1983]
(h) u-ya-ba-khétisa
'you help them choose'
(i) u-ya-yị-límísisa
'you plow it intensively'

\subsection{Metrical analysis of antepenultimate prominence and tone shift.} There is plenty of evidence, then, that the antepenult in Nguni attracts high tones, at least in nouns, infinitives, and verbs in the Present Continuous Tense. (I will confine my discussion to these forms, since they are the ones for which underlying tone patterns are most transparent and for which I have the most data in all three languages.) This ability of a particular syllable to attract a high tone has parallels in other Bantu languages. Kisseberth [1984] and Sietsema [1989] have argued that the final syllable of words in Digo attracts high tones, for example. Kenstowicz and Kisseberth [1990] have shown that the penult attracts high tones in ChiZigula, and Peterson [1987] and Goldsmith [1987] have argued that stem- 
initial and stem-final syllables attract high tones in other Bantu languages, as well. As argued by Goldsmith [1987], metrical rules, which are designed to assign prominence to certain syllables of words or phrases, seem a phonologically natural way to pick out which syllables will attract high tones, and all of the analyses just mentioned (except Kisseberth [1984]) have therefore adopted a metrical approach.

A metrical analysis of Nguni antepenult tone shift has, in fact, been proposed by Goldsmith, Peterson, and Drogo [1986] for Xhosa and extended to Ndebele and Zulu by Peterson [1989b], who point out that the antepenult is a common, natural location for prominence to be realized. In their analysis, the antepenult is assigned an accent by metrical rules like those given in (8) (a schematic representation of the effect of the rules is also given):

(8) Accent Placement Rules (Preliminary Version)

(a) Mark final syllables extrametrical (i.e., invisible to metrical rules (Hayes (1982)) by enclosing them in angled brackets. Word-final syllables are extrametrical in Xhosa, but only phrase-final syllables are extrametrical in Zulu and Ndebele.

(b) Construct a left-headed binary foot at the right edge of a word.

(c) Assign an accent $(*)$ to the metrically strong syllable.

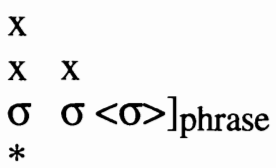

The domain of spread of the rightmost high tone can now be defined with reference to the accented syllable:

\section{(9) Metrical Tone Spread}

Spread a high tone rightwards to the metrically prominent (accented) syllable.

In Zululand Zulu only the antepenult surfaces with a high tone, so one might propose that the high tone associates directly to the accented syllable. But the other Nguni languages provide evidence that high tones are associated by the UAC to the morpheme-initial syllable and then spread to the accented syllable, instead of associating directly to it. In Xhosa [Claughton 1983] and in the Natal dialect of Zulu [Rycroft 1979], the vowels between the underlyingly high-toned vowel and the accented target of Metrical Spread (9) may optionally be realized with a high tone. Further, in Ndebele delinking does not apply if the high tone 
subject to Metrical Spread is originally linked to the word-initial syllable (as in $(3,4,6)$, above). To account for the fact that in all the languages the antepenult is often the only syllable which surfaces with a high tone, however, a delinking rule must apply to the outcome of Metrical Tone Spread (9) to disassociate all except the rightmost branch of the resulting multiply-linked high tone. The minor variations among the three languages in the application of delinking are listed as conditions on the rule as follows:

\section{(10) Leftbranch Delink}

Delink all but the rightmost branch of a multiply-linked high tone. (Optional in Xhosa and Natal Zulu; does not apply if the leftmost branch is linked to a word-initial syllable in Ndebele.)

The application of rules (8-10) is illustrated in the derivation of (3d) given in (11):

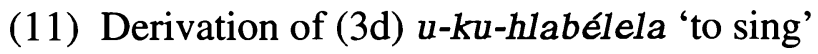

UR, UAC

Accent Assignment

Metrical Tone Spread

Leftbranch Delink

SR

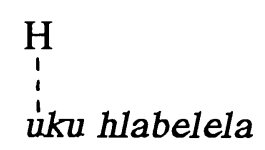

$\mathbf{H}$

uku hlabele $<l a>_{\text {extrametrical }}$

*
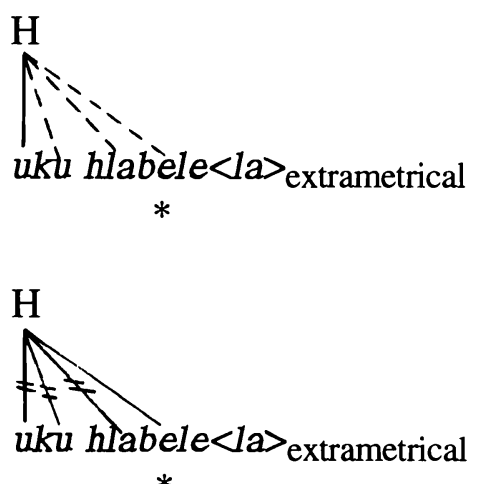

*

ukuhlabélela 'to sing' 
1.4. Metrical Shift as a phrase-level rule. One last point I would like to make about antepenult tone shift is to explain why I argue, following Peterson [1989b], that it is a post-lexical rule for Zulu and Ndebele and claim that only the phrase-final syllable is marked extrametrical for the grid-building rules in those languages (but word-final syllables are always extrametrical for the data discussed here in Xhosa). The evidence for this comes from the data in (12):

(12) Low verb stem with high-toned subject prefix, Indicative tense, phrase-medial forms (verb has form: SP-stem)

$\underline{\text { Zulu }}$
(a) ba-limísa
'they help plow'
(b) $\underline{u}$-hlekísa
's/he amuses'
(c) u-shukumísa
's/he shakes'
(d) $\underline{u}$-namathelísa
's/he makes stick'

Ndebele

(e) ú-hlákúla

's/he weeds'

$\underline{\text { Xhosa }}$
(f) lí-bálisa
's/he recounts'
(g) lí-shúkúmisa
's/he shakes'

These are the phrase-medial forms of the low verbs with high-toned subject prefixes given in (6). If we compare the two sets of verbs, we note that the tense/aspect marker -ya- is absent from the forms in (12) and that the rightmost high tone surfaces on the penult in Zulu and Ndebele, instead of on the antepenult as it did in (6). Since word-final syllables are always extrametrical in Xhosa, the antepenult is still assigned the accent in phrase-medial forms like those in (12) and pre-antepenultimate high tones shift to the antepenult in both phrase-medial and phrase-final forms. The phrase-medial shift to the penult in Zulu and Ndebele is also straightforwardly accounted for by the rules given so far. While every high-toned word is assigned prominence by the rule of Accent Placement (8), as a post-lexical rule it may be sensitive to phrase boundaries which are only visible at that level of the phonology. Since only phrase-final syllables are extrametrical for Accent Placement, then phrase-medially the final syllable of the words in (12) is no longer on the periphery of a metrical domain. It is thus no longer invisible to metrical rules [Hayes 1982], and accent is assigned to the penult. This is shown in the derivation of (12a) given in (13): 
(13) Derivation of (12a) ba-limísa 'they help plow' (phrase-medial form)

$\mathrm{H}$

UR, UAC

Extrametricality

Accent Placement

Metrical Tone Spread

Leftbranch Delink

SR ba limisa

Not applicable

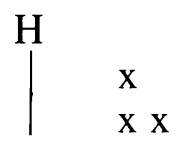

ba limisa

$*$

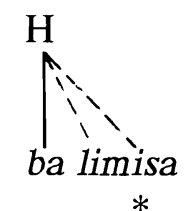

*

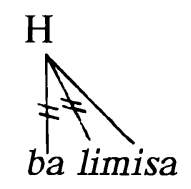

balimísa 'they help plow'

The derivation of (12e) ú-hlákúla 's/he weeds' (Ndebele) would also proceed as in (13), except that Left Delink (10) would not apply since the high tone is originally linked to a word-initial syllable.

More research is necessary to determine what exactly constitutes a phonological phrase in Zulu and Ndebele, but the "short" form of a Present Continuous verb and the following word, at least, seem to form a phrase, making the final syllable of the verb exempt from extrametricality.

\section{Local Tone Shift}

2.1. Evidence in favor of Local Shift. In this section, I will argue that antepenult shift is not the only tone shift process applying in Nguni. Evidence for this comes from the data below, in which a high tone originally linked to the an- 
tepenult has shifted to the penult even though, as I argued in the preceding section, the antepenult is a metrically strong position:

(14) Antepenult to penult shift (all of the following examples are from Zulu, but Ndebele and Xhosa cognates are identical, except for variations in Left Delink (10))

1. Preprefix or subject prefix before monosyllabic $\mathrm{N}$ or $\mathrm{V}$
(a) $\underline{u}-k u ́-l w a$
'to fight'
(b) u-yá-lwa
'he fights'
(c) $\underline{u}-l u ́-h l a$
'row, line'
(d) $\underline{u}-m u ́-n t u$
'person'

2. Object prefix (high-toned) preceding low CVCV (disyllabic) verb stem
(e) u-ya-wạ-bála
'you count it'
(f) si-ya-yi-líma
'we plow it'

3. Stem-initial syllable of a trisyllabic high verb or noun

Underived stems
(g) ku-sẹbénza
'to work'
(h) ku-khạthála
'to get tired'
(i) si-sebénzi
'worker'
(j) si-phämbáno
'cross, crucifix'

Derived stems
(k) ku-theng-ísa
'to sell'
(1) ku-bon-ísa
'to show'
(m) m-buzz-ána
'small goat'
(n) si-boshw-ána
'small cord'

In Nguni monosyllabic stems are relatively rare, but the other two cases of antepenult to penult shift are very common. Disyllabic verb stems are the canonical type of Bantu verb, so low-toned disyllabic verbs preceded by an object prefix make up a very large group of forms to account for. Underived trisyllabic stems are less common than disyllabic, but trisyllabic stems may be derived from disyl- 
labic stems by adding suffixes. The verbal suffixes, or extensions, are especially productive, and in Zulu and Ndebele the high tone on the antepenult of all derived and underived trisyllabic verb stems systematically shifts to the penult. In Xhosa verbs and nouns, and in Zulu and Ndebele nouns, too, the antepenult high tone shifts in all underived stems and in most derived stems.

There are, then, a sizeable number of cases in the Nguni languages where a high tone on the antepenult predictably shifts one syllable to the right. To account for antepenult to penult shift, Nguni must have not only a metrical tone spread rule (10), but also a rule of local tone spread, formulated below:

\section{(15) Local Spread}<smiles>OCNO</smiles>

This rule spreads a high tone one syllable to the right, and then the rule of Leftbranch Delinking (10), which applies under the same conditions mentioned above, deletes the leftmost branch of the multiply-linked high tone to derive shift. Since high tones associated with the penult do not shift to the final syllable either phrase-finally or medially, the word-final syllable would appear to be extratonal, that is, invisible for tone spread (but this will be revised in \$3.2). Even if an accent is assigned to the antepenult after Local Shift (but this, again, will be revised in §2.5), Metrical Spread (9) will not be able to apply to the high tone placed on the penult by Local Shift because tones may only spread rightwards to the accented syllable.

The application of local shift is illustrated by the derivation of (14f), given in (16) (note that syllables in parentheses are extratonal, while those in angled brackets are extrametrical):

(16) Derivation of (14f) si-ya-yi-líma 'we plow it'

UR, UAC

Extratonality

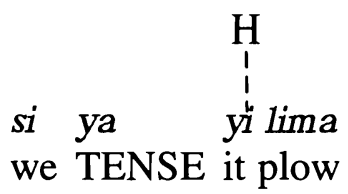

$\mathrm{H}$

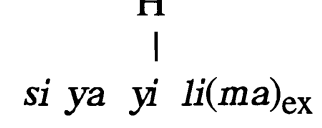


Local Shift

Accent Assignment

Metrical Tone Spread

SR si ya yi $\stackrel{\text { fi }(m a)_{\mathrm{ex}}}{\mathrm{f}}$

$$
\begin{array}{ccc} 
& & \mathrm{H} \\
\text { si ya } & \text { yi } & l i<\operatorname{ma}>_{\mathrm{ex}} \\
\mathrm{x} & \mathrm{x} \\
\mathrm{x} &
\end{array}
$$

Not applicable

si-ya-yi-líma 'we plow it'

The other cases of antepenult to penult shift illustrated by the data in (14) would have an analogous derivation.

Local Spread must apply before Metrical Spread, since the rule does not apply to high tones shifted to the antepenult, but only to those originally associated with the antepenult. If Local Spread applied after Metrical Spread, all high tones would be shifted to the penult, as shown by the incorrect derivation of (3d) given in (17) (compare with (11)):

(17) Incorrect Derivation of (3d) u-ku-hlabélela 'to sing' (Metrical Shift preceding Local Shift)

UR, UAC

Accent Assignment

Metrical Tone Spread
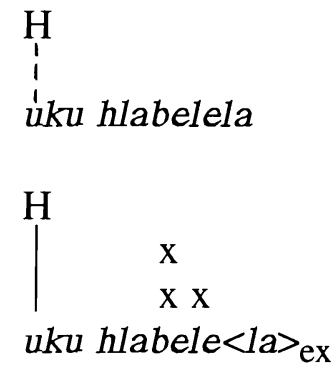

*

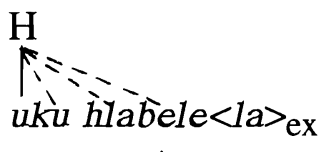


Left Delink

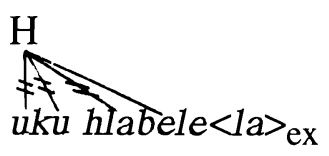

Local Shift

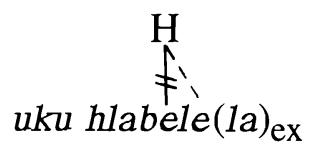

SR

*uku hlabeléla 'to sing'

The rules which I have proposed to account for Nguni tone so far are summarized below:

(18) Tone Rules for Nguni

Local Tone Rules

Extratonality (word-final syllable)

Local Tone Spread (15)

Leftbranch Delink (10)

Metrically-Conditioned Tone Rules

Extrametricality (word-final syllable in Xhosa; phrase-final syllable in Zulu and Ndebele)
Assignment of Accent (8)
Metrical Tone Spread (9)
Leftbranch Delink (10)

2.2. Earlier metrical analyses. An important difference between this analysis and other recent autosegmental analyses of Nguni tone (Clark [1988]; Khumalo [1987]; Goldsmith, Peterson, and Drogo [1986]; Peterson [1989b]) is that this analysis has two rules shifting high tones rightward: a local rule, which shifts high tones one syllable to the right, and a metrical rule, which shifts a high tone to a metrically prominent syllable, i.e. the antepenult, after local shift has applied. In this section, I will show that the analysis proposed here, in which a local tone shift rule precedes assignment of metrical structure, provides a more general and more natural account of the Nguni data than the earlier metrical analyses presented in Goldsmith, Peterson, and Drogo [1986] and Peterson [1989b]. These two analyses provide an insightful account of metrical tone shift in Nguni, and, as mentioned in $\S 1$ above, I have adopted their formulation of metrical tone shift in the present paper. They have problems, however, in treating cases of antepenult to penult shift which the present analysis has accounted for 
using the rule of local shift. The drawbacks of each of these approaches will be discussed in turn.

2.2.1. Goldsmith, Peterson, and Drogo's [1986] analysis of Xhosa. Goldsmith, Peterson, and Drogo [1986] present an analysis of some of the Xhosa verb forms published in Claughton [1983] and are the first, as far as I know, to give a metrical analysis of antepenult tone shift in an Nguni language. This paper discusses two cases of antepenult to penult tone shift: first, shift of the high tone of some trisyllabic verb stems from the initial (antepenult) to the second (penult) syllable, and, second, shift of the high tone of OP's to the initial syllable of lowtoned CVCV (disyllabic) verb stems. An example of each of these cases is cited below:

(19) Antepenult to penult shift in Xhosa verbs [Claughton 1983]

1. Trisyllabic high verb stems
(a) ku-bónísa
'to show'

2. OP preceding low CVCV stem (verb has form: SP-TM-OP-stem)

(b) ni-ya-wạ-bála

'I count them'

Although Claughton [1983] only cites these two examples of Local Shift, other available Xhosa literature (Westphal and Notschweleka [1967], Louw [1971] and Lanham [1958]) confirms that they are systematic.

Goldsmith, Peterson, and Drogo [1986] analyze both of these cases of antepenult to penult tone shift as cases of accent shift rather than tone shift. That is, all trisyllabic stems like those in (19a) and all disyllabic stems like those in (19b), which represent, in fact, the vast majority of disyllabic and trisyllabic verb stems in Xhosa, are lexically marked to trigger the following rule of accent-hopping, which shifts the accent from the antepenult to the penult after the antepenult has been assigned prominence by rules like those in (8):

(20) Accent Hopping [Goldsmith, Peterson, and Drogo 1986], fig. (6)

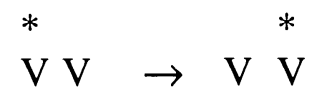

A rule of Attraction to Accent, formulated like Metrical Spread (9), will then apply, allowing the underlying antepenultimate high tones of words like those in (19) to spread to the penult. Thus, in this analysis, both low-toned and hightoned verbs include a class of lexically-marked "Accent Hoppers", which are 
predicted to always attract high tones preceding the accent to the penult instead of the antepenult by triggering rule (20). 5

This prediction is incorrect in the case of the low CVCV (disyllabic) "AccentHopping" stems, however. In fact, these disyllabic low stems only trigger accent hop when they are preceded by an OP. Other high tones preceding the stem which are in pre-antepenultimate position, such as the high tone on the subject prefix (SP) lí-in (6g) li-yá-bala 's/he counts' or the high tone on the infinitival pre-prefix ú-in (3e) u-kú-bala 'to count', shift only to the antepenult, not to the penult. As shown in the derivation of $(6 \mathrm{~g}) l i$-yá-bala 's/he counts', the accent hop analysis allows these pre-antepenultimate high tones to surface one syllable to the right of where they actually occur:

(21) Incorrect derivation of (6g) li-yá-bala 's/he counts', Accent Hop Analysis

UR, UAC

Accent Placement

Accent Hop

Metrical Tone Shift $(9,10)$

SR

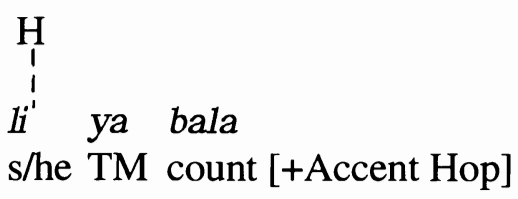

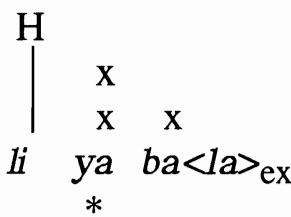

$\mathrm{H}$

li ya $b_{*}<<l a>$ ex

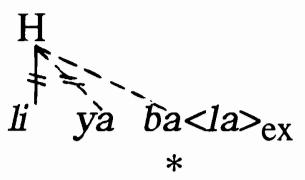

*liyabála 's/he counts'

5 Another problem with having Accent Hop be a lexically-triggered rule is that it fails to explain why words derived from the "accent-hopping" stems do not also trigger accent hop as would be expected if this is truly a lexical property of the stems. For example, -bonisa 'to show' triggers Accent Hop (20), but when an extension is added to derive -bonisisa 'to show clearly', the high tone surfaces on the antepenult. Likewise, in the low stems, -wa-bála 'count them' triggers Accent Hop (20) to the penult, but the derived stem + OP, -wa-bálisa 'recount to them' does not. 
The Local Shift analysis, on the other hand, accounts for this form straightforwardly. As shown below, Local Shift $(15,10)$ will apply first to shift the high tone of 11 - one syllable rightward. Accent Placement (8) will then assign metrical prominence to the antepenult, but since the antepenult is already linked with a high tone after Local Shift, Metrical Spread (9) is inapplicable and the high tone correctly surfaces on the antepenult:

(22) Derivation of (6g) li-yá-bala 's/he counts', Local Shift Analysis

UR, UAC

Local Shift

Accent Placement

Metrical Tone Spread

SR
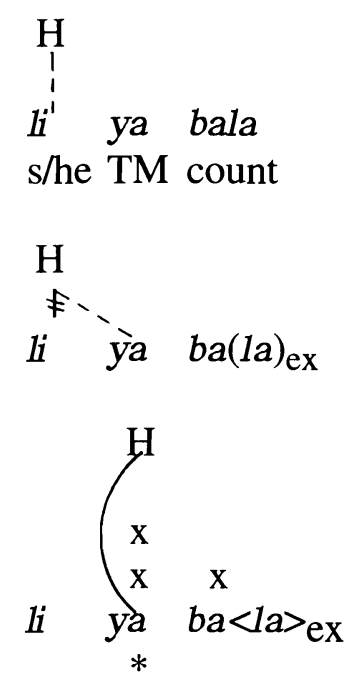

not applicable

liyábala 's/he counts'

In short, although a single rule of local tone shift, applying before accent placement, accounts correctly for all the Xhosa data, a single rule of accent shift applying after accent placement does not. ${ }^{6}$ In positing a class of accent-hopping

6 In fact, there is an accent shift rule which could correctly predict the Nguni data, namely one which shifted an accent off a vowel which was (underlyingly) associated with a high tone onto the next vowel rightwards:

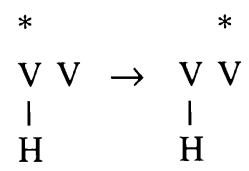


low verb stems, Goldsmith, Peterson, and Drogo [1986] incorrectly predict that all high tones preceding the stems will shift to the penult (stem-initial) syllable, while in fact only high tones originally associated (by the UAC) to the antepenult shift to the penult.

2.2.2. Peterson's [1989b] analysis of Ndebele and Zulu. Peterson [1989b] extends the metrical analysis of Xhosa tone presented in Goldsmith, Peterson, and Drogo [1986] to two other Nguni languages, Ndebele and Natal Zulu, taking as her sources Rycroft [1983] for the former and, chiefly, Cope [1970] for the latter. Prominence in both languages is still assigned to the antepenult by accent placement rules like those given in (8), above, but antepenult shift (see data in 19) is no longer accounted for by a single rule of Accent Shift. Instead, Accent Shift is formulated to move the accent placed on the antepenult to the penult just in case the stem is trisyllabic and high-toned:

(23) Accent Shift [Peterson 1989b], fig. (7)

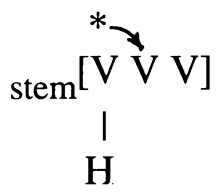

Metrical Spread (Attraction to Accent, in Peterson's terminology) then spreads the high tone to the accented penult. Peterson [1989b] does not discuss the noun data presented in her source, Rycroft [1983], but presumably this same rule could apply to the trisyllabic noun stems which undergo local shift (see (14), above). Since in Xhosa some trisyllabic verb stems undergo Accent Shift while others do not, those which do undergo the rule are to be marked in the lexicon, just as they were in the previous analysis.

To derive shift of the high tone of an OP before disyllabic low-toned verbs, Peterson [1989b] abandons the accent shift approach and instead proposes that a rule of high tone displacement applies to place the high tone of the OP on the following (i.e. verb stem initial) syllable before metrical prominence is assigned to the word. Although this rule is not formalized in Peterson [1989b], note that it has the effect of Local Shift $(15,10)$ in this context and is likewise ordered before accent placement. Since high-toned penults receive metrical prominence in this analysis, the high tone displacement rule leads to assignment of prominence to the penult of low disyllabic stems which follow an OP,7 as illustrated by the

While this accent shift rule would derive the correct results, it has theoretical drawbacks which will be discussed in $\$ 2.4$.

7 It is not clear from Peterson's [1989b] discussion why OM Displacement does not feed Accent Shift (23) when the object prefix precedes a low-toned trisyllabic stem as in u-ya-bá-khetisa $\rightarrow$ u-ya-ba-khéthisa 'you help them choose'. After OM high tone displacement, -khéthisa is a 
following derivation (based on Peterson's [1989b] discussion of the Ndebele form, u-ya-yi-khétha 'you choose it'):

(24) Derivation of u-ya-yi-khétha 'you choose it'

UR, UAC

OM High Displacement

Accent Placement

Attraction to Accent

SR
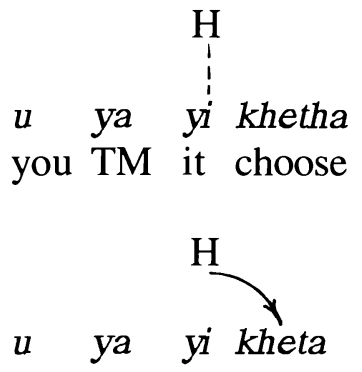

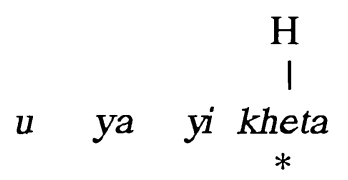

not applicable

u-ya-yi-khétha 'you choose it'

In sum, while Peterson's [1989b] analysis derives the correct results, she is forced to propose two processes which account for the same facts that the single process of local shift accounts for, one of which (Object Marker High Displacement) has the effect of a local tone shift rule applying before metrical prominence is assigned. Since the Local Shift analysis argued for in this paper provides a more general account of Nguni tone, it is clearly to be preferred.

\subsection{Arguments against the accentual rules first hypothesis} (Goldsmith [1982] and Sietsema [1989]). Peterson seems to have rejected having an explicitly formulated tone shift rule applying before Accent Placement, because she [Peterson 1989a] adopted the hypothesis, proposed in Goldsmith [1982] and also defended in Sietsema [1989], that tone and accent form independent systems in tone languages, with all metrical rules preceding all local (nonmetrical) tonal rules. Under this hypothesis, all accent rules apply to the UR, so that initial tone association in accentual languages is mediated by accents, i.e. accented tones associate with accented syllables or, to rephrase this according to the 
current interpretation of accent [Goldsmith 1987], unassociated high tones associate to metrically prominent (accented) syllables. It is only after tones are associated to accented syllables that non-metrical tone rules may apply to derive the surface tone patterns. This approach is too restrictive, however, because non-metrical tone rules can be shown to precede metrical rules both in the other metrical analyses of Nguni and in other Bantu tone languages.

First, it is evident that in Nguni, accent/metrical prominence (I have been using these two terms interchangeably) does not mediate initial tonal association. Instead, high tones are either linked underlyingly (when association is not predictably to the morpheme-initial syllable, as in the case of nouns like si-khathí 'time') or by the UAC (when association is predictably with the morpheme-initial syllable, as in verb stems). Accent rules apply after tonal association to define the domain of spread of (certain) high tones. Since association conventions and, in Peterson [1989b], a high tone displacement rule must apply before metrical rules do, a model in which all tone linking and displacement occur after all accentual rules apply cannot be maintained for Nguni.

Secondly, the Nguni languages are not the only Bantu languages in which a non-metrical tone rule can be argued to precede metrical rules. ChiZigula, an Eastern Bantu language spoken in Tanzania, has received a similar analysis [Kenstowicz and Kisseberth 1990]. In ChiZigula, it is the penult which is argued to be assigned metrical prominence, since, as illustrated in (25) below, the rightmost high tone generally surfaces on that syllable even though it may originally be associated several syllables to the left:

ChiZigula high-toned infinitives

$\begin{array}{ll}\text { ku-1ombéza } & \text { 'to ask' } \\ \text { ku-lombez-éz-a } & \text { 'to ask for' } \\ \text { ku-lombez-ez-án-a } & \text { 'to ask each other for' }\end{array}$

However, high tones underlyingly associated with the penult do not surface on the penult, so that disyllabic high and low stems are neutralized, both surfacing as low. (In ChiZigula, as in Nguni, the verb's high tone associates with the stem-initial syllable.) Only when extensions are added to the stems does the high-low contrast become apparent, as illustrated in (26): 
(26) Neutralization of ChiZigula disyllabic stems

Low stem

ku-guh-a

'to take'

but

ku-guh-il-a 'to take for'
High stem

ku-fis-a 'to hide'

ku-fis-íz-a 'to hide for'

Kenstowicz and Kisseberth [1990] argue that penult high tones come to be deleted as the result of the application of two rules, both of which are shown to have independent motivation. First, the high tones shift to the final syllable, and then final high tones are deleted from a metrically weak position, as shown in the derivation of kufisa 'to hide' given in (27):

(27) ChiZigula: Derivation of ku-fis-a 'to hide'

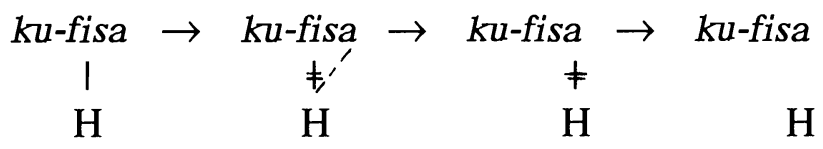

In ChiZigula, as in Nguni, then, a high tone originally associated with the normally accented syllable (in this case the penult) shifts rightward one syllable. The ChiZigula local tone shift rule must apply before the metrical "attraction to accent" rule because otherwise the rightmost high tone would always be shifted to the final syllable and then deleted. Instead, only high tones underlyingly on the penult spread to the final syllable.

The tone system of Digo, another Eastern Bantu language spoken in Tanzania, shows many similarities to that of ChiZigula. As Kisseberth [1984] showed, the rightmost high tone in Digo induces a rise-fall tone pattern over the last two syllables of a word, even though the high tone may originally have been associated several syllables to the left:

(28) Digo high-toned infinitives

$\begin{array}{ll}k u-c h \underline{e} k \text { ěchâ } & \text { 'to sift' } \\ k u \text {-chekechěrâ } & \text { 'to sift for/with' } \\ k u \text {-chenkecherănâ } & \text { 'to sift for one another' }\end{array}$

Kisseberth [personal communication] would now analyze the attraction of the high tone towards the end of the word in Digo as in the analysis of ChiZigula just discussed, by assigning metrical prominence to the penult. (Note that this contrasts with Kisseberth's [1984] analysis of Digo which posits that the final syllable 
attracts high tones.) Another similarity with ChiZigula is that in Digo disyllabic high and low stems are neutralized, both surfacing as low. The high-low contrast is evident, however, when extensions are added to the stems:

(29) Neutralization of Digo disyllabic stems

Low Stem

ku-rima

but 'to cultivate'

'to cultivate for'
High Stem

ku-tsuna 'to skin'

ku-tsunǐrâ 'to skin for/with'

Neutralization of disyllabic stems in Digo may be analyzed as resulting from the same two-step process as was found in ChiZigula. First, penult high tones shift to the final syllable, and then final high tones are delinked, as shown in the derivation of ku-tsuna 'to skin', given in (30):

Digo: Derivation of ku-tsuna 'to skin'

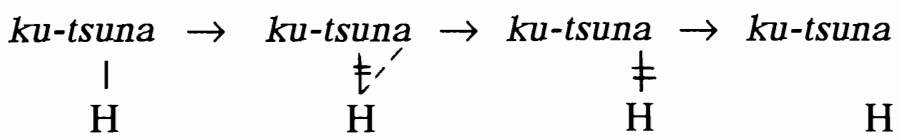

While I could find no other clear cases of local tone shift (though indirect support for a local tone shift rule will be presented in \$3.2), independent evidence for final high tone deletion comes from the fact that CV stems, like ku-tya 'to eat', which Kisseberth [1984] argues have an underlying stem high tone on the final syllable, also surface as low.

In Digo and ChiZigula, too, then, a high tone associated with the normally accented syllable shifts rightward one syllable. Just as we found in Nguni, this local tone shift rule must apply before a metrical tone spread rule because otherwise the rightmost high tone would always be shifted one syllable too far to the right. To account for these cases, phonological theory must allow non-metrical tone rules to precede metrical (accentual) rules. A model, like that proposed by Goldsmith [1982] and Sietsema [1989], in which all metrical rules must precede all non-metrical rules, cannot account for these cases and thus cannot be maintained as a universal principle of grammar.

2.4. The Naturalness of Local Shift vs. Accent Shift. Another reason for preferring the local tone shift analysis of Nguni tone presented here over the accent shift analyses of Goldsmith, Peterson, and Drogo [1986] and Peterson [1989b] is that tone shift provides a simpler, more natural way of accounting for 
shift of high tones to an immediately adjacent syllable than Accent Shift $(20,23)$ does. Since accents in tone languages represent prominence assigned by metrical stress rules, we would expect Nguni accent shift to be motivated by the same factors which generally condition stress shift. In fact, the rules of accent shift proposed for Nguni would represent quite unusual examples of stress shift.

For one thing, even though in both accent shift analyses of Nguni high-toned syllables must be metrically heavy and attract prominence in order for high-toned penults to be assigned an accent (as, for example, after OM High Displacement, discussed in \$2.2.2., above; see also discussion in \$2.5., below), the rule of accent shift ((20), (23), and see note 6) moves the accent off a heavy (high-toned) syllable onto a light (low-toned) syllable. While it is common [Hayes 1980] for heavy syllables to attract prominence, it is certainly unusual for heavy syllables to repel prominence in the absence of any other motivating factors.

Indeed, another striking thing about the proposed Nguni accent shift rules is that they are lexically-triggered and not motivated by the factors which commonly induce stress shift. Hayes's [1980] and Halle and Vergnaud's [1987] surveys of stress in a number of languages show that stress shift is generally motivated by metrical structure or by a change in the segmental material available for metrical parsing. A type of stress shift motivated by metrical structure is stress clash. The English Rhythm Rule [Halle and Vergnaud 1987], for example, shifts a main word stress to the left in compounds with adjacent main stresses, so that:

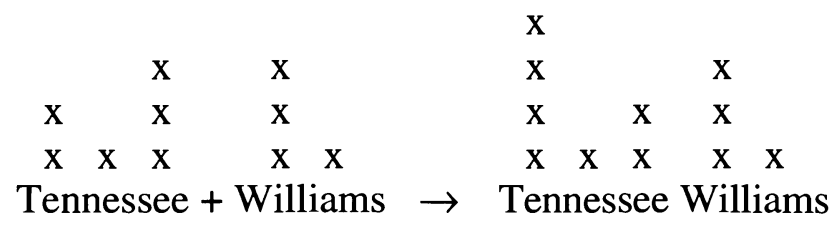

An example of stress shift motivated by a change in the segmental material available for metrical parsing is found in Tiberian Hebrew (for details, see Halle and Vergnaud [1987]). In this language reduction or deletion of a stressed vowel causes stress shift to the right, so that:

$$
\begin{array}{ccc}
\mathrm{x} & \mathrm{x} \\
\mathrm{x} \quad \mathrm{x} \text { x } & \mathrm{x} & \\
\text { katabuu } & \rightarrow & \text { kaat'buu }
\end{array}
$$

Neither of these conditions motivate Accent Shift $(20,23)$ in Nguni.

Since there is no metrical motivation for Accent Shift in Nguni, one wonders why Peterson [1989b] accounts for antepenultimate to penult tone shift by an accentual rule in the case of trisyllabic high stems but by a tone displacement rule in the case of object prefixes preceding low CVCV stems. (While it is true that OM High Displacement applies to object prefixes in other contexts as well, the only 
context in which it has an effect different from metrical tone shift is when the object prefix precedes a low CVCV stem.) As we have seen in \$2.2.1., positing that both trisyllabic high stems and low CVCV stems trigger accent shift would give the wrong results, but no criteria are presented for choosing a priori when tone displacement rather than accent shift is the appropriate device for shifting high tones rightward. Metrical factors, in any case, do not seem to be decisive, and Accent Hop and Accent Shift $(20,23)$ remain unusual prominence shift rules.

Tone spread and tone shift (spread followed by delinking), on the other hand, are extremely common tonal rules. Hyman and Schuh [1974] list them as among the most natural and frequently found tone rules. Indeed, in the domain of Bantu tone alone, language after language has been analyzed as having a rule of nonmetrical tone spread or tone shift: ChiZigula [Kenstowicz and Kisseberth 1990], Jita [Downing 1990], Nyamwezi [Nurse 1979], Qhalaxari (Sotho) [Dickens 1984], Rimi [Schadeberg 1979], Ruri [Goldsmith 1986], Shambala [Meeussen 1955], Shona [Myers 1987], Setswana [Kisseberth and Mmusi 1989], and Tsonga [Louw 1983], to name only a few. (It is worth noting that most of these languages do not have a rule of metrically-conditioned tone spread or tone shift, suggesting that local spread or shift is the older Bantu rule, while metrical spread is an innovation.) The local shift analysis proposed here for Nguni has ample parallels in other Bantu languages, then, supporting a claim that non-metrical tone shift is a more natural way of displacing a high tone one syllable to the right than accent shift in the absence of any metrical factors which might condition accent shift.

2.5. Do local rules feed metrical rules in Nguni? If local tone rules precede metrical rules in Nguni, one final question which arises is how the metrical rules apply to the output of local shift. That is, after local shift has applied, do the metrical rules still assign prominence to the antepenultimate syllable as shown in derivation (16)? If the antepenult is assigned prominence, this predicts that, in a word with two high tones like
a. ú-ku-sébenza
'to work'

once the rightmost high tone shifted to the penult by local shift, the other would shift to the prominent antepenult, to derive

$$
\text { b. * } \underline{u}-k u-s \underline{e} b \underline{e} n z a
$$

But this form does not occur in any of the Nguni languages. Instead, the leftward high tone may only spread one syllable to the right in Zululand Zulu (the comparable Xhosa and Ndebele tone patterns will be discussed in the next section), i.e. it undergoes local shift to derive 


\section{c. $\underline{u}-k u ́-s \underline{e} b e ́ n z a$}

We need, then, to block Metrical Spread from applying to any except the rightmost high tone of a word in order to avoid deriving incorrect forms like (32b) above. One way of doing this would be to add a stipulation to the rule of Metrical Spread such that the rule only applied to the rightmost high tone of a word:

\section{(33) Possible revision of Metrical Spread}

The rightmost high tone of a word spreads rightwards to the accented syllable.

The disadvantage of this approach is that Metrical Spread is now so narrowly defined that the accent is assigned to the antepenult vacuously in most cases (as in (16) and (32c), above). Further, the prominent syllable is no longer the one bearing the rightmost high tone, either, which was one generalization we wanted to capture with the metrical approach to antepenult shift.

A way to maintain the generalization that the rightmost high tone is associated with the prominent syllable would be to complicate the rules assigning metrical prominence. As mentioned above, Goldsmith, Peterson, and Drogo [1986] and Peterson [1989b] have suggested that in Nguni high-toned penult syllables may be considered heavy for the assignment of prominence. Hayes [1980] noted that treating high-toned syllables as heavy for stress assignment is also necessary in Fore [Nicholson and Nicholson 1962] and Golin [Bunn and Bunn 1970], so this strategy does have cross-linguistic motivation. In this approach, the metrical rules for Nguni would be similar to those for Latin: stress the penult if it is heavy (high-toned), otherwise stress the antepenult. Adapting Halle and Vergnaud's [1987:55-59] stress rules for Latin, the rules for Nguni prominence would be as follows:

\section{Accent Assignment in Nguni (Revised)}

a. Mark the (phrase-) final syllable extrametrical.

b. Assign a line 1 asterisk to high-toned syllables.

c. Construct binary, left-headed feet right to left.

d. Assign a line 2 asterisk to the rightmost asterisk on line 1.

e. Assign an accent to the syllable bearing the line 2 asterisk. 
A word with two high tones like (32a) in which the rightmost high tone is originally associated with the antepenult would be assigned metrical structure as follows:

(35) Metrical Prominence Assignment, ú-ku-sébenza 'to work'

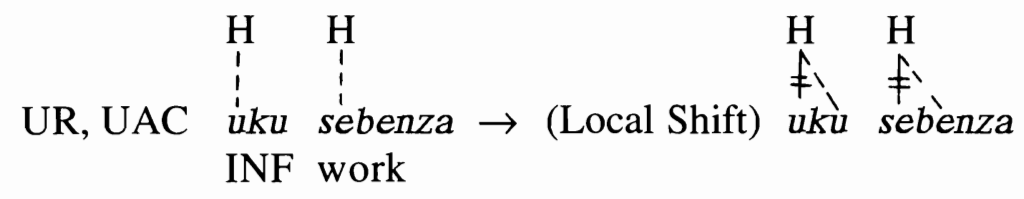

Metrical Rules (34a-e)

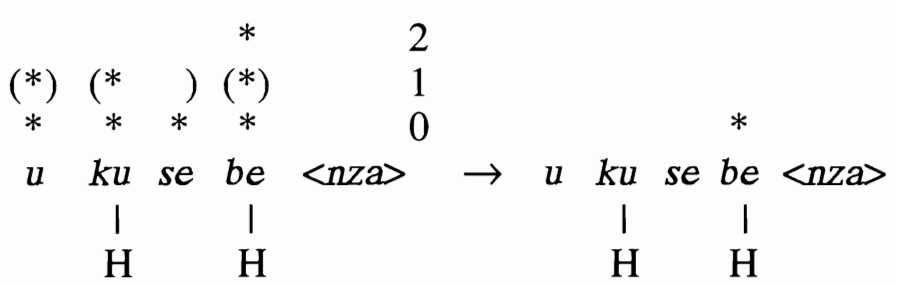

In cases where the rightmost high tone is associated with the antepenult or a preceding syllable after Local Shift, the antepenult would still be assigned prominence and, if unassociated, attract a high tone by Metrical Spread as in the derivation in (12), above.

Zulu and Xhosa do not exactly parallel the Latin prominence system, however, because the few trisyllabic noun stems with a high tone on the final syllable also block prominence assignment to the antepenult. As shown in the example below, the high tone of the preprefix shifts only one syllable to the right:

$$
\begin{array}{ll}
\text { á-ma } & \text {-shininí } \rightarrow \text { amá-shininí 'factories' (Zulu and Xhosa) } \\
\text { Cl.6 factory } &
\end{array}
$$

If the final syllable were extrametrical so that the antepenult were assigned prominence, this word would surface as *a-ma-shíniní. To account for the fact that local shift, not metrical shift, applies to the leftmost high tone of words like these, we may revise (34a) so that only light, i.e. low-toned, final syllables are marked extrametrical. (See Downing [1989] for a similar condition on extrametricality.) This would allow the high-toned final syllable of words like (36) to be assigned prominence, so only Local Spread could apply to the leftward high tone.

In order for these rules to derive the correct results, I am assuming that Metrical Spread will not apply if the accented syllable is already associated with a 
high tone. This condition on a similar rule of Attraction to Accent was postulated for ChiZigula [Kenstowicz and Kisseberth 1990], and it may well be a universal constraint on this type of rule. Otherwise, we may revise Metrical Spread as follows:

\section{(37) Metrical Spread (Final Version)}

A high tone spreads rightwards to an adjacent accented syllable (which is not already linked with a high tone).

\section{Exceptions to Tone Shift}

3.1. Words with Two High Tones. I have just shown that in some Zulu and Xhosa words with two high tones, the leftmost high tone may undergo local shift, as in the following examples:

(38) Local Shift in Words with Two High Tones
a. Zulu infinitives: ú ku sébenza $\rightarrow$ u kú sebénza
'to work'
b. Zulu and Xhosa nouns: á ma shininî $\rightarrow$ amá shininí 'factories'

Local shift does not apply to the leftmost high tone of every word with two high tones, but, as I will show in this section, these apparent exceptions to local shift have a straightforward phonological explanation.

3.1.1. Meeussen's Rule. The first set of apparent exceptions to local shift discussed in this section involves words in which the two high tones are adjacent, such as high-toned verb stems preceded by an OP or high-toned SP. In Nguni, all Object Prefixes have a high tone, as shown by the data below:

(39) Low verb stem with object prefix, Indicative tense (form of verb is SP-TM-OP-stem):

$\underline{\text { Zulu }}$
(a) u-ya-wáa-bála
'you count them'
(b) u-ya-ngi-hlékisa
'you amuse me'
(c) si-ya-wa-shukúmisa
'we shake them'
(d) si-ya-wa-namathélisa
'we make them stick' 
Xhosa [Claughton 1983]
(e) ni-ya-wáá-lwa
'I fight them'
(f) ni-ya-wạ-bála
'I count them'
(g) ni-ya-wa-bálisa
'I recount to them'
(h) ni-ya-wä-shúkúmisa
'I shake them'
(i) ni-ya-wa-námáthélisa
'I cement them'

Ndebele [Rycroft 1983]
(j) u-ya-yi-khétha
(k) u-ya-ba-khéthisa
(1) u-ya-yí-limísisa
'you choose it'
'you help them choose'
'you plow it intensively'

Since the verb stems and subject prefixes are toneless, the only high tone in the above data must be contributed by the object prefix. Local shift applies to shift the high tone of the object prefix onto the initial stem vowel of the verb, and in quadrisyllabic or longer stems (39c, d, h, i, l), Metrical Spread (8) applies to shift the object prefix (OP)'s high tone to the antepenult. (Note that in Xhosa, Left Delink (10) is obligatory for high tones linked to an OP.)

In cases where a high-toned OP precedes a high-toned verb stem, only one high tone surfaces, as shown by the data in (40):

(40) High-toned infinitives (short form) with and without high-toned object prefixes
A. Without object prefixes
B. With object prefixes
(a) ku létha
'to bring'
(b) ku zị létha 'to bring them'
(c) ku béka
'to put'
(d) ku wa béka 'to put them'
(e) ku lẹthéla 'to bring to'
(f) ku ba $\underline{a}$ lethéla 'to bring to them'
(g) ku bonísa 'to show'
(h) ku wa bonísa 'to show them'
(i) ku khulúmisa
(j) ku ba khullúmisa 

'to speak to'
'to speak to them'
(k) ku nyingyithékisa
'to make slippery'
(1) ku wa nyịnyithékisa
'to make them slippery'

These data show that when two high tones are adjacent in Nguni, one high tone seems to be deleted.

The deletion of a high tone if it is adjacent to another high tone is a widespread process in Bantu and has been given the name Meeussen's Rule by Goldsmith [1984]. As Myers [1987] argues, Meeussen's Rule can be motivated by the Obligatory Contour Principle (OCP) which prohibits identical adjacent feature specifications within certain morphological domains [Leben 1973]. Since many Object Prefixes are high-toned in Bantu languages and the Object Prefix usually immediately precedes the verb stem, a high-toned verb stem preceded by a high-toned Object Prefix is a common context for the application of Meeussen's Rule. Often, it is the stem high tone which is deleted by Meeussen's Rule (see Goldsmith [1984] for examples), but the Object Prefix's high tone may also be deleted, as it is in ChiZigula [Kenstowicz and Kisseberth 1990]).

The deletion of one of the two adjacent high tones in the data in (40B) may then be attributed to Meeussen's Rule, and the trisyllabic stems $(40 \mathrm{e}, \mathrm{g})$ provide evidence that it is the OP's high tone which deletes. If the stem high tone deleted, neither Local Spread (15) nor Metrical Spread (8) could spread the OP's high tone past the stem-initial (antepenultimate) syllable, and both low- and high-toned verb stems would have identical tone patterns when preceded by an object prefix. Instead, in high-toned trisyllabic verbs, the high tone surfaces on the penult, as is predicted if the OP's high tone is deleted and local shift applies to the remaining stem-initial high tone. To account for the data in (40), Meeussen's Rule in Nguni must delete the first of two adjacent high tones, as shown below:

\section{Meeussen's Rule (preliminary version)}

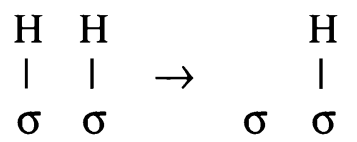

Note that the longer stems $(40 \mathrm{e}, \mathrm{g}, \mathrm{i}, \mathrm{k})$ provide further evidence that the stem high tone is originally associated to the initial syllable by the UAC and not directly associated to the accented syllable. Otherwise the OP high tone and the stem high tone would not be adjacent in these cases, and it would be very difficult to generalize about the context in which the OP's high tone is deleted.

Complications with the formulation of Meeussen's Rule in (41) arise when we look at further data, however. In the phrase-medial form of the Present Indicative, discussed above (see (12)), the tense/aspect marker is absent, so the 
subject prefix is added directly before the verb stem (or "super-stem", which includes the OP). If high-toned subject prefixes (SP) are added to high-toned verb stems or super-stems in this tense, up to three adjacent high tones result, as shown in the words below:

(42) Short form of the Present Indicative (verb has form: High-toned SP (-OP) -High Verb Stem )

$\underline{\text { Zulu }}$
(a) $\underline{u}$-ba-phakkamísa
(b) bạ-khullumisána
(c) $\underline{u}$-si-fundísa
(d) si-yi-níka

's/he lifts them'
'they speak to, recip.'
's/he teaches us'
's/he (Cl. 6) gives it'

Xhosa

(e) lí-wáa-béka

's/he puts them'

(f) lí-wa-bónísa

's/he shows them'

(g) lị-wạ-bónísisa

's/he shows them clearly'

Ndebele [Rycroft 1983]

(no examples with OP were cited)

(h) báa -létha

'they bring'

(i) ú-sébénza

's/he works'

(j) bá-bónísána

'they show each other'

The penult is accented in the phrase-medial form of the Present Indicative in Zulu and Ndebele (see $§ 1.4$., above), so the data from those languages cannot tell us which high tone(s) have been deleted: the surviving high tone would spread to the penult in any case. Only the Xhosa trisyllabic form (42f) shows clearly that it is the rightmost of the underlying high tones which survives, since only Local Spread (15) of the rightmost underlying high tone may account for the high tone on the penult instead of the antepenult (compare ( $42 \mathrm{f}$ and $\mathrm{g}$ )). Meeussen's Rule (41) must then be allowed to apply iteratively left to right in order to derive the correct results for all the Zulu and Xhosa words in (42). The Ndebele data in (42i-1) still present complications for the rule in (41), however, because the subject prefix (and following syllables) surface with a high tone. As noted above, in Ndebele Leftbranch Delinking (10) is always blocked if the leftmost branch of a multiply-linked high tone is associated with a word-initial syllable, and it appears that this same constraint must be extended to block application of Meeussen's 
Rule: it does not apply if the target of deletion is linked to a word-initial syllable. A way of unifying these two observations about the special status of word-initial high tones in Ndebele is to propose that Meeussen's Rule does not delete all but the rightmost of a series of adjacent high tones. Instead, Meeussen's Rule should be formulated like the OCP Tone Fusion Rule proposed by Kisseberth and Mmusi [1989] for Setswana to fuse a series of adjacent high tones (e.g., that of the OP and verb stem) into a single, multiply-linked high tone, as shown below:

(43) Meeussen's Rule (Tone Fusion Version)<smiles>[Y]C=[V]</smiles>

Local Spread (15) next applies to this multiply-linked high tone to spread it one more syllable rightward, and finally Left Delink (10) applies to all except its rightmost branch. The usual constraint on delinking word-initial high tones would apply in Ndebele to derive the tone patterns in $(42 \mathrm{~h}-\mathrm{j})$. Since the Tone Fusion version of Meeussen's Rule also derives the correct tone patterns for the Xhosa and Zulu data, it is the version I will adopt in this paper. The application of Meeussen's Rule (43) is illustrated by the derivation of (40f) ku-ba-lethéla 'to bring to them', below:

(44) Derivation of (40f) ku-ba-lethéla 'to bring to them' (short form)

$$
\mathrm{H} \quad \mathrm{H}
$$

UR

ku- ba- leth- ela

INF them bring applied suffix

UAC

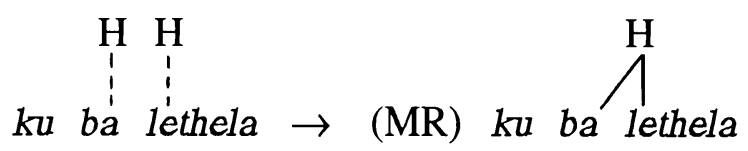

$\rightarrow$ (Local Shift) ku ba lethela $\rightarrow$ (SR) kubalethéla

3.1.2. OCP-motivated delinking. In many words with two high tones in Zulu and Xhosa, the leftmost does not seem to undergo local shift, even though both high tones surface and the context for the rule is met. For example, in Xhosa, local shift never applies to the high tone of the nominal/infinitival agree- 
ment preprefix or to the subject prefix before a stem with a high tone on the stem-initial syllable, as illustrated below:

(45) Xhosa nouns and verbs with two high tones (no shift)

Verbs
(a) u-ku-béka
'to put'
lí-ya-béka
's/he puts'
(b) ú-ku-bónísa 'to show'
lí-ya-bónísa
's/he shows'
(c) ú-ku-bónísisa
'to show clearly'
lị-ya-bónísisa
's/he shows clearly'

\section{Nouns}

(d) á-ma-séla 'thieves'

(e) á-ba-fúndisi 'teachers'

Even in Zulu, local shift only optionally applies in forms like those cited in $(45 b, c)$ in which the stem high tone undergoes local shift (see (32c), above). Otherwise, the tone patterns are identical to Xhosa with no spread of the leftmost high tone.

The generalization we can make about the data in (45) is that Local Spread fails to apply when the syllable following the target for spread has a high tone. That is, Local Spread does not apply in the following configuration:

\section{(46) Constraint on Local Spread}<smiles>C[18O]O[O-]</smiles>

In fact, other Southern Bantu languages, including Shona [Myers 1987] and the SeSotho/Tswana group (ongoing research under C. Kisseberth at the University of Illinois), have a similar constraint on Local Spread. Myers [1987] has argued for Shona that this constraint may be motivated by the OCP, since, if the first high tone spreads, it will create two adjacent high tones. Local Spread may be blocked in this context by having the constraint in (46) act as a condition on Local Spread (this is the approach taken by Myers [1987]). Alternatively, Local Spread may be allowed to apply, and a rule of OCP-motivated Right-Branch Delinking (OCP Delink) could undo the effects of spread, as shown below (this is the approach taken by Kisseberth and Mmusi [1989] for Setswana): 
(47) OCP (Rightbranch) Delink<smiles>C[18O]C(=O)O</smiles>

I will adopt the OCP Delink approach in this paper, but no empirical evidence favors that approach over a constraint on spread as proposed by Myers [1987].

The application of OCP Delink to account for the surface lack of spread of the leftmost high tone in (45) is illustrated by the derivation of (45b) below:

(48) Derivation of (45b) ú-ku-bonísa 'to show' (Xhosa)

UR, UAC

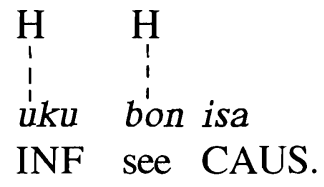

Local Spread

$\begin{array}{cc}\mathrm{H} & \mathrm{H} \\ \mathrm{I} & \mathrm{I}\end{array}$

Extrametricality uku boni(sa)

OCP Delink uku boni(sa)

$\begin{array}{ccc} & \mathrm{H} & \mathrm{H} \\ & \mathrm{I} & \neq \\ \text { Leftbranch Delink } & \mathrm{uku} & \text { boni(sa) }\end{array}$

SR úkubonísa 'to show'

OCP Delink must apply before Leftbranch Delink in Xhosa, because otherwise Leftbranch Delink (10) would bleed OCP Delink by disassociating the conditioning high tone, as shown by the incorrect derivation of (45b) given below: 
(49) Incorrect derivation of (45b) ú-ku-bonísa 'to show' (Xhosa)-Leftbranch Delink before OCP Delink

UR, UAC<smiles>[14CH3][TlH]</smiles>

Local Spread

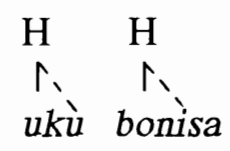

Leftbranch Delink

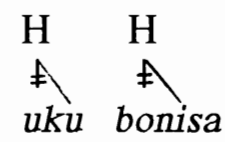

OCP Delink not applicable

SR

*ukú bonísa to show'

In order for local shift to be able to apply optionally in the Zulu cognates of words with longer high-toned stems like (45b,c; 32c), however, Leftbranch Delink must precede and bleed OCP Delink. To account for this difference between Zulu and Xhosa, Left Delink (10) could be ordered before OCP Delink in Zulu, so that the derivation of (32c) u-kú-sebénza 'to work' would proceed like the incorrect derivation for the Xhosa form given in (49), above. Alternatively, Local Spread and the two delinking rules could apply cyclically, as illustrated in the derivation of (32c) given in (50):

(50) Derivation of (32c) u-kú-sebénza 'to work' (cyclic application of Local Shift and Right Branch Delink)

\section{$\mathrm{H} \quad \mathrm{H}$}

UR

uku sebenza

Cycle 1

UAC, Extrametricality sébe(nza) $)_{\mathrm{ex}}$ 
Local Spread

OCP Delink

Leftbranch Delink

Cycle 2

UAC, Local Spread

OCP Delink

Leftbranch Delink

SR

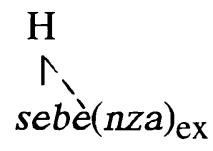

not applicable

$$
\begin{aligned}
& \mathrm{H} \\
& \text { A } \\
& \text { sebe }(n z a)_{e x}
\end{aligned}
$$

A potential problem with having these rules apply cyclically is that they apply within non-derived roots, like -sebénza 'work', appearing to violate the strict cycle condition (SCC) [Kiparsky 1985]. However, these stems with an initial high tone do not have the high tone linked underlyingly, since the Universal Association Convention (2) associates the high tone with the morpheme-vowel automatically. Only non-initial high tones need to be lexically linked. As Levergood [1984] has argued, the application of association conventions like the UAC may create a derived environment and thus feed the morpheme-internal application of cyclic prosodic rules like tone spread. The cyclic analysis proposed in (50) would therefore be consistent with the SCC. The difference between Xhosa and Zulu which accounts for the different tone patterns in (45b) and (32c), then, could either be that in Zulu Local Spread and the delinking rules are cyclic rules, while in Xhosa they are non-cyclic, or simply that in Zulu Left Delink precedes OCP Delink, while in Xhosa the rules apply in the opposite order.

In Ndebele words with two high tones, we find different tone patterns from those in Zulu and Xhosa. While Meeussen's Rule applies to delete the leftmost of two adjacent high tones (see the data in (40), above), in the case of non-adjacent high tones, the leftmost high tone spreads iteratively up to the syllable immedi- 
ately preceding the high tone linked to the accented syllable, as shown by the data below [Rycroft 1983]:

(51) Ndebele, High Prefix $+\mathrm{H}$ stem, $\mathrm{N}$ and V
a. u-kú-léthísa
'to help bring'
b. 뜨-yá-létha
's/he brings'
c. u-yá-hlólísisa
's/he examines intensively'
d. îsí-hámbi
'traveller'
e. ísí-khwámána
'small bag'

Thus, it appears that constraint (46) does not hold in Ndebele, since high tones may spread onto a syllable adjacent to another high tone. The leftmost high tone also may spread over several syllables in these words, not just one, as in Zulu and Xhosa, so some rule other than Local Spread seems to be applying. Following Peterson [1989b], I account for these facts by proposing that Ndebele has an iterative tone spread rule, formulated below, which is ordered after Metrical Spread (9) and Leftbranch Delink (10):

\section{(52) Iterative Spread}

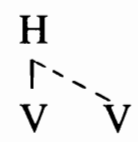

i.e. a high tone not linked to a metrically prominent syllable spreads iteratively to a toneless vowel. 8

Left Delinking (10) does not reapply to the output of this rule. This could fall out from the fact that Iterative Spread (52) is ordered after Delinking (10). Alternatively, it could be due to the fact that, in all the data available to me, Iterative Spread applies to word-initial high tones, so the context for Delinking (10) is not met.

Having three ordered tone spread rules may make Ndebele seem unusually complex, but ChiZigula [Kenstowicz and Kisseberth 1990] has also been analyzed as requiring a local tone shift rule, a metrical shift rule and an iterative spread

\footnotetext{
8 In Ndebele there is some evidence that final high-toned syllables are still extrametrical, unlike in Zulu and Xhosa (see \$2.5., above). Prefixal high tones in the antepenult preceding monosyllabic stems do not undergo iterative tone spread: ú-ya-phá $\rightarrow$ ú-ya-phá 's/he gives'. This can be accounted for if the final syllable is extrametrical and the antepenult is assigned an accent. Since iterative spread (52) does not apply to high tones linked to the accented syllable, the leftmost high tone fails to spread.
} 
rule, applying in that order. The Ndebele system thus has parallels in another Bantu language. Also, in this analysis, Ndebele is actually only minimally different from Zulu and Xhosa. Local Spread is restricted to apply within the domain of the "super-stem" in Ndebele (this is again like ChiZigula). High tones not linked to a metrically prominent syllable after metrical shift (and local shift, of course) undergo a third spread rule, Iterative Spread (52).

To sum up this section, some apparent exceptions to local shift in words with two high tones in Zulu and Xhosa may be easily accounted for by postulating that Meeussen's Rule fuses a series of adjacent high tones before Local Spread and Delink Apply. Other apparent exceptions likewise receive a straightforward explanation if a delinking rule (47) undoes Local Spread in Zulu and Xhosa when its output creates two adjacent high tones. This constraint on Local Spread is, in fact, widespread in Southern Bantu, and has been argued by Myers [1987] to be motivated by the OCP which prohibits adjacent identical feature specifications within a single morphologically-defined domain. Left Delink (10) was able to bleed OCP Delink (47) in some environments in Zulu, however, leading to many more apparent exceptions to Local Spread in Xhosa than in Zulu. Ndebele was shown not to have this constraint on Local Spread, and further to have an iterative tone spread rule (52) which applied to the leftmost of two high tones after local shift and metrical shift had applied. Thus, although the surface tone patterns of Ndebele, Xhosa and Zulu are quite different from one another in words with two high tones, these differences can be shown to result from relatively minor differences in their grammars. Another important point about these apparent exceptions is that the analysis presented here allows us to see clear parallels between Nguni and other Bantu languages, including ones (Shona, SeSotho/Tswana) not analyzed as having metrical tone rules. Even if a purely accentual analysis of these Nguni facts proves to be possible (and none has, to my knowledge, been attempted), it would surely obscure these similarities.

\subsection{High-toned stems with (underlying) long vowels. Another context} in which local shift apparently fails to apply is when the initial high tone of some derived trisyllabic stems does not shift to the penult as predicted by local shift. In Zulu and Ndebele, only some trisyllabic noun stems are exceptions, while all trisyllabic verb stems regularly undergo local shift; but in Xhosa exceptions can be found among both noun and verb stems. The data below give examples of shifting and non-shifting trisyllabic noun and verb stems in Nguni: 
(53) Nguni Trisyllabic Noun and Verb Stems (short form of the infinitival or nominal prefix)

Zulu and Ndebele

Verb Stems (all trisyllabic verb stems undergo local shift)
(a) ku-sébénza
'to work'
(b) ku-bon-ísa
'to show'
(c) ku-le th-ísa
'to help bring'
(d) ku-fund-ísa
'to teach'

Shifting Noun Stems

(e) si-sẹbénzi

'servant; worker'

(f) si-khwạm-ána

'small bag'

Non-Shifting Noun Stems

(g) n-tw-ány-ana

'tiny thing'

(h) ma-sél-ana

'small thieves'

Xhosa

Shifting Verb Stems
(i) ku-bón-ísa
'to show'
(j) ku-sébénza
'to work'

Non-Shifting Verb Stems
(k) ku-búl-isa
'to greet'
(l) ku-fúnd-isa
'to teach'

Shifting Noun Stems
(m) si-sébénzi
'servant; worker'
(n) si-khwạm-ána
'small bag'

Non-Shifting Noun Stems
(o) n-tw-ány-ana
'tiny thing'
(p) ma-sél-ana
'small thieves' 
As discussed in §2.1.1 above, Goldsmith, Peterson, and Drogo [1986] accounted for the two patterns in Xhosa by arguing that the non-shifting stems $(53 \mathrm{~g}, \mathrm{~h}, \mathrm{k}, \mathrm{l}$, $\mathrm{o}, \mathrm{p}$ ), in which the rightmost high tone surfaces on the antepenult, were the regular pattern, while the shifting stems were lexically marked to undergo a rule of Accent Hop (20). Peterson [1989b] has taken the position that in Ndebele, all trisyllabic stems undergo Accent Shift (23), and presumably (since she did not discuss nominal tone) the non-shifting noun stems would be lexically marked as exceptions to Accent Shift. In this section I will argue that all the non-shifting stems historically - and underlyingly - have long stem-initial vowels, and in fact, do undergo Local Shift.

An important point about the non-shifting trisyllabic stems is that only some derived stems are exceptions to local shift. Non-derived trisyllabic stems all undergo local shift, so that there are no non-derived trisyllabic stems which surface with the stem high tone on the stem-initial syllable [J. Khumalo, personal communication]. If we examine the stems from which the data in (53) are derived, we find that there is a corresponding contrast in their tone patterns. Instead of the more typical (see, for example, Greenberg [1948]) Bantu contrast between low- and high-toned disyllabic verb stems, Nguni has a further two-way split in the high-toned stems. In Zulu and Xhosa, some stems have a level high tone on the stem-initial syllable, while others have a falling contour, while in Ndebele the split is between stems whose initial high-toned syllable is optionally realized with a low tone and stems whose initial syllable is always high-toned. This is shown by the data below:

(54) Nguni disyllabic high-toned infinitives

$\underline{\text { Zulu }}$
(a) ku-bônna
'to see'
(b) ku-khûlla
'to grow up'
$v s$.
(c) ku-létha
'to bring'
(d) ku-fúnda
'to learn'

Xhosa
(e) ku-mêma
'to invite'
(f) ku-bônna
'to see'
$v s$.
(g) ku-béka
'to put'
(h) ku-fúnda
'to learn' 


\section{$\underline{\text { Ndebele }}$}
(i) ku-bóna/ku-bonna
'to see'
$v S$.
(j) ku-létha
'to bring'

As illustrated in (55) below, the shifting trisyllabic stems are derived from disyllabic stems which, in Xhosa and Zulu, have a falling contour on the penult phrase-finally and in Ndebele have a level high tone optionally pronounced with a low tone $(55 \mathrm{~b}, \mathrm{~d})$. The non-shifting trisyllabic stems, on the other hand, are derived either from monosyllabic stems (55f) or from disyllabic stems with a level high tone on the penult in all three languages and no optional low-toned pronunciation in Ndebele $(55 \mathrm{~h}, \mathrm{j})$.

(55) Sources of Shifting vs. Non-Shifting Trisyllabic Stems (Ndebele pronunciation follows $\sim$; words have form: Class Agreement prefix-root-suffix(es))

Shifting
(a) si-khwam-ána
(b) si-khwâma si-khwáma/si-khwama
(c) ku-bon-ísa
(d) ku-bôna ku-bóna/ku-bona

\author{
'small bag' \\ 'to show' \\ 'to see'
}
'bag

Non-Shifting

(e) $n$-tw-ány-ana

(f) $n$-tó $\sim n-t o ́ / n-t o$

(g) ma-sél-ana

(h) ma-séla ma-séla

(i) ku-fúnd-isa ku-fúnd-isa

(j) ku-fúnda ku-fúnda

As Westphal [1951] and Rycroft [1980a] have argued, the split in high-toned disyllabic stems in Nguni between those with a level high tone and those with a falling contour (or level high tone with optional low tone in Ndebele) on the penult has an historical explanation. The disyllabic stems with a level high tone are regularly derived from Proto-Bantu roots with stem-initial long vowels ("long initial vowel" roots), while the stems with a falling contour (or high alternating with low tone in Ndebele) are derived from Proto-Bantu roots with stem- 
initial short vowels ("short initial vowel" roots). Some examples from Rycroft [1980a] are cited below:

(56) Proto-Bantu roots and Nguni cognates (Ndebele pronunciations which differ from Zulu and Xhosa follow )

$\begin{array}{lll}\text { Proto-Bantu } & \text { Nguni } & \\ \text { (a) *-béek- } & \text {-bék- } & \text { 'put' } \\ \text { (b) *-búudi- } & \text {-búz- } & \text { 'ask' } \\ \text { (c) *-dáad- } & \text {-lál- } & \text { 'sleep, lie down' } \\ \text { (d) *-déet- } & \text {-léth- } & \text { 'bring' } \\ \text { (e) *-bón- } & \text {-bôn- -bón-/-bon- } & \text { 'see' } \\ \text { (f) *-kúd- } & \text {-khûl- -khúl-/-khul- } & \text { 'grow up' } \\ \text { (g)*-dúm- } & \text {-lûm- -lúm-/-lum- } & \text { 'bite' } \\ \text { (h)*-tún- } & \text {-fûn- -fún-/-fun- } & \text { 'desire' }\end{array}$

An interesting point about the short initial vowel roots is that, in some contexts, they undergo a rule of high tone deletion which otherwise only applies to words with a high tone on the final syllable. In Zulu, final high tones are deleted phrase-medially, and in Ndebele Rycroft [1983] states that final high tones may be deleted in all contexts, so that in many instances, it is only when the root is extended by adding suffixes that the underlying high tone is realized (compare (55a,b, 55c,d, 55e,f)). Final High Tone Deletion in Zulu and Ndebele is illustrated by the data below (insufficient data was available for Xhosa):

(57) Final High Tone Deletion (applies phrase-medially in Zulu; the phrasemedial forms may occur in all contexts in Ndebele)

\section{Phrase-Final}

(a) si-khathí

(b) ku-pháá

(c) zi-njá

\section{Phrase-Medial}

$\begin{array}{ll}\text { si-khathi } & \text { 'time' } \\ \text { ku-pha } & \text { 'to give' } \\ \text { zi-nja } & \text { 'dogs' }\end{array}$

Short initial vowel roots also have their high tone deleted phrase-medially in Zulu, and do so optionally in all contexts in Ndebele, showing the same sort of neutralization with low stems already seen in ChiZigula and Digo (see §2.3., above): 
(58) Final High Deletion, short initial vowel roots (applies phrase-medially in Zulu; the phrase-medial forms may occur in all contexts in Ndebele; precedes Ndebele forms)

\section{Phrase-Final}

(a) ma-bûtho ma-bútho

(b) si-khwâma si-khwáma

(c) n-kâbi n-kábi

(d) ku-fûnda ku-fúnda
Phrase-Medial

$\begin{array}{ll}\text { ma-butho } & \text { 'warriors' } \\ \text { si-khwama } & \text { 'bag' } \\ \text { n-kabi } & \text { 'ox' } \\ \text { ku-funda } & \text { 'to want' }\end{array}$

Data like those in (58) have led many Nguni scholars (Clark [1988], Claughton [1983], Khumalo [1987], Peterson [1989a]) to posit that the short initial vowel stems have a high tone both on the penult syllable and the final syllable. The high tone on the penult is needed to derive the fall (in Zulu and Xhosa) or level high tone (in Ndebele verb stems-see (55d)) on that syllable and to account for the fact that OCP Delink applies before these stems (the long form of (55d), for example, is ú-ku-bôna 'to see'), as does Meeussen's Rule (32) (ku-wá-bôna $\rightarrow$ kuwa-bôna 'to see them', short form). The high tone on the final syllable explains why these stems undergo Final High Deletion in Zulu and Ndebele. Clark [1988] and Khumalo [1987], to take the most recent autosegmental analyses which discuss this problem, therefore propose that the difference between the disyllabic high-toned stems with a level high tone $(55 \mathrm{~h}, \mathrm{j})$ and those with a falling contour (or high alternating with low, in Ndebele) $(55 \mathrm{~b}, \mathrm{~d})$ is that the high tone of the former is unlinked in underlying representation, while that of the latter is underlyingly linked to the penult and final syllables, as shown below:

(59) Representation of high-toned stems in Nguni

a. Level High on Penult ( $\rightarrow$ non-shifting stems)

$\mathrm{H}$

$\begin{aligned} k u[\text { letha] } \quad & \rightarrow \text { ku-létha } \\ & \rightarrow \text { ku-léth-isa }\end{aligned}$

'to bring'

'to help bring' (Xhosa)

b. Falling contour or optional all low ( $\rightarrow$ shifting stems)

$$
\begin{array}{lll}
\wedge u \text { bbona] } & \rightarrow \begin{array}{l}
\text { ku-bôna (Zulu and Xhosa) } \\
\sim \text { ku-bóna/ku bona (Ndebele) }
\end{array} \\
& \rightarrow \text { ku-bon-ísa }
\end{array}
$$


The derivation of a falling contour from the representation in (59b) seems to be triggered by stress-induced lengthening of the penult. Although I have not indicated this in the transcriptions, phrase-penult syllables are lengthened in Nguni as in many other Southern Bantu languages [Doke 1954], so the falling contour (the phrase-final tone pattern) is realized only on lengthened penults. When stress-induced lengthening applies, penults with a singly-linked high tone simply undergo spread of that high tone to the second mora of the lengthened vowel. But when stress-induced lengthening applies to the representation in (59b), an ill-formed representation is derived, since the high tone is no longer linked to adjacent moras. Tone spread to the second mora of the lengthened vowel is blocked in this case, and instead the rightbranch of the high tone delinks. Default low tones are associated with the free vowels, deriving the falling contour, ${ }^{9}$ as shown in (60):

(60) Derivation of the falling-contour from (59b)

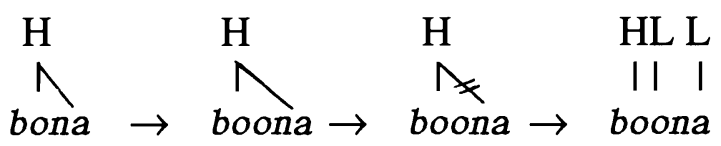

(For other possible derivations of the falling contour, see Clark's [1988] and Khumalo's [1987] discussions of Zulu tone.) In any case, the representation in (59b) does not undergo Leftbranch Delinking in the cases where the penult is realized with a falling contour (Zulu and Xhosa) or a level high tone (Ndebele), but it does in the contexts (phrase-medially in Zulu, optionally everywhere in Ndebele) where Final High Tone Deletion applies, ${ }^{10}$ so that Leftbranch Delinking may feed Final High Tone Deletion to derive neutralization with low-toned stems:

\footnotetext{
${ }^{9}$ Kisseberth [personal communication] suggests that rightward delinking of the high tone might be triggered by the presence of a phrase-final (boundary) low tone. (Peterson [1989] has also suggested that a boundary low tone could be somehow responsible for the contour tone in these forms, but she did not explicitly formulate rules to derive the contour.) This is an appealing hypothesis, and future research may well show it to be well-motivated. For example, Downing [1989] has argued that investigating the tone pattern of questions is a fruitful method of testing processes attributed to the presence of phrase-final low tones.

10 It is worth noting here that there is one apparent exception to the general condition in Ndebele that Leftbranch Delinking does not apply if the leftmost branch of the high tone is linked to a wordinitial syllable, namely, when the word-initial syllable is also the penult. Rycroft [1983] notes that the form úphá 'he gives' (phrase-medial form) surfaces as upha. This may be accounted for as follows: Meeussen's Rule (43) would fuse the high tone on the subject prefix (ú- 'he') with that of the stem (-phá 'give'), and then Leftbranch Delinking would apply, even though the leftmost branch of the high tone is linked to the word-initial vowel. Final High Deletion would delete the remaining high tone, deriving the surface tone pattern.
} 
(61) Derivation of (58a) ma-butho 'warriors' (phrase-medial form)
(UR) ma butho $\rightarrow$ (Left Delink) ma butho
$\mathrm{H}$
$\neq$
$\quad$ (Final H) ma butho $\rightarrow$ (SR) ma butho

Although the representations in $(59 \mathrm{a}, \mathrm{b})$ do account for some of the differences between the two types of high-toned stems in Nguni, one problem with these representations is that they do not give any insight into the historical development of the two different tone patterns. Why would the less common long initial vowel roots have come to have the simpler representation in (59a), while the majority of disyllabic stems (namely, the short initial vowel roots) came to have the complex representation in (59b)? Further, why should (some) trisyllabic stems derived from disyllabic stems with the representation in (59a) fail to undergo local shift? The fact that those which are derived from stems with the representation in (59b) do undergo local shift is accounted for by allowing the multiply-linked representation to carry over to words derived from these stems. After Leftbranch Delink (11) applies, the effect of local shift is achieved (see Clark [1988], Khumalo [1987] for details). But there is nothing about the representation in (59a) which could block local shift in derived trisyllabic stems.

The key to the split in Nguni high-toned stems and the trisyllabic exceptions to local spread can be found by looking at similar facts in other Bantu languages. According to Meeussen [1955], Shambala also has a two-way split in the high-toned verb stems which may be traced to the Proto-Bantu vowel length contrast. Due to a very general local tone spread rule found in Shambala, most disyllabic high-toned stems surface with a high tone on both syllables, as shown below:

(62) Local Spread in Shambala disyllabic stems

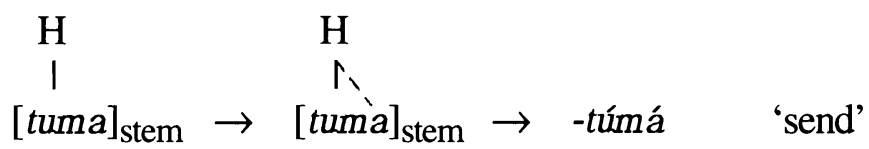

Other verbs with this tone pattern are
(a) -lóghá
'to fish' 

(b) -víná
'to dance'
(c) -téghá
'to trap'

But some high-toned disyllabic stems surface with a high tone only on the first syllable. That is, they seem not to undergo local spread:

(63) Shambala stems which fail to undergo spread [Meeussen 1955]
(a) -léta
'to bring'
(b) -lóta
'to dream'
(c) -lála
'to lie down'
(d) -úza
'to ask'

Meeussen [1955] argues that the stems in (63) all developed from Proto-Bantu long initial vowel roots (note that (63a) is a cognate of Nguni -létha 'bring' (see (56d), above). He proposes that local spread did apply to these stems when they still retained the Proto-Bantu length contrast, the high tone spreading from the first to the second mora of the initial syllable. The long vowel of the stem was shortened after local spread had applied, leaving a high tone only on the initial syllable:

(64) Derivation of -léta [Meeussen 1955]

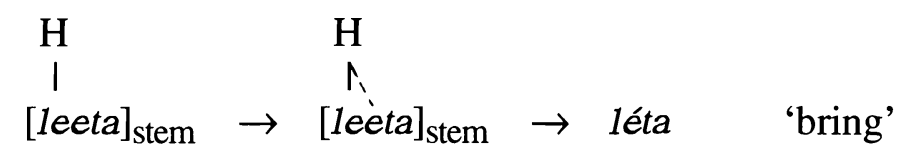

Shambala is not the only Bantu language for which it may be argued that a two-way split in the high-toned verbs resulted from historically long initial vowel roots failing to undergo a rule of high tone spread. In Qhalaxari, a Sotho language in the South Bantu group analyzed in Dickens [1984], some high verbs (High 1) have a high tone only on the first syllable of the stem, while others (High 2) have a high tone on the first two syllables of the stem:

(65) Qhalaxari high-tone verb patterns [Dickens 1984:110, Table 2]

High 1 verbs
(a) -já
'eat'
(b) -búzha
'ask'
(e) -bóná
'see'
(f) -xúpúla
'remember'

High 2 verbs 

(c) -húmula
'rest'
(g) -khúrúmula
'uncover'
(d) -húmulela
'rest in/at'

The high tone on the second syllable of the verbs in the High 2 group is derived by a rule of High Spread like the Shambala rule illustrated in (62). The stems in the High 1 group apparently fail to undergo this High Spread rule, but, as Dickens argues, these verbs are regularly derived from long initial vowel Proto-Bantu roots (note that (65b) is a cognate of (63d)). The failure of High 1 verbs to undergo High Spread can be accounted for like Meeussen does for the Shambala data: High Spread applied to these stems before the Proto-Bantu vowel length contrast was lost in Qhalaxari.

Digo [Kisseberth 1984] provides yet another example of a language in which words derived from Proto-Bantu long initial vowel roots fail to undergo tone spread. As shown in (29), above, in Digo most disyllabic high stems neutralize with the low stems due to the rules of local shift followed by final high tone deletion also found in ChiZigula. But in Digo, unlike ChiZigula, some high stems are exceptions to local shift and subsequent final high deletion and surface with the same rise-fall pattern on the last two syllables as longer high stems (compare with (28), above):

(66) Digo disyllabic exceptions to neutralization [Kisseberth 1984:117, fig. 14]
a. $k u$ rẹ̆hâ
'to bring'
b. ku kwě्râ
'to climb'
c. ku fündâ
'to teach'

As Kisseberth [1984] showed, these exceptions are regularly derived from Proto-Bantu long initial vowel roots (note (66a) is a cognate of (56d)). Again, it could be argued that in Digo, as in Shambala and Qhalaxari, the exceptional tone pattern of the stems in (66) may be accounted for if local shift applied to them before Proto-Bantu vowel length was lost. The stem high vowel would only shift from the first to the second mora of the long initial syllable, and the context of final high deletion would not be met.

A final example of a Bantu language in which words derived from ProtoBantu long initial vowel roots fail to undergo a regular rule of tone shift is Rimi [Schadeberg 1979]. Rimi, like Shambala, Qhalaxari, and Digo, has a two-way split in its high-toned verb stems. As shown by the data below, some (67A) undergo a rule of local shift and surface with a high tone on the second syllable of the stem, while others (67B) do not and surface with a high tone on the first stem syllable: 
(67) Rimi High Tone Verb Patterns [Schadeberg 1979]

A. Verbs undergoing local shift
(a) -oná
'see'
(b) -rumá
'bite'
(c) -ímbá
'sing'
(d) -tümá
'send'

B. Verbs showing no tone shift
(e) -ótea
'dream'
(f) -éta
'bring'
(g) -híta
'refuse'

(Note that the data in (67A) are phrase-medial forms. Phrase-finally, Final High Deletion applies to these disyllabic stems, leading to neutralization with low stems by the same two-step process (Local Shift followed by Final High Deletion) already seen in ChiZigula and Digo.)

As Schadeberg [1979] demonstrates, all the stems which fail to undergo shift (67B) are derived from Proto-Bantu long initial vowel roots, while the stems which do undergo shift (and neutralize phrase-finally) derive from the short initial vowel roots. The lack of surface shift in the stems in (67B) can again be accounted for if their high tones shifted from the first to the second mora of the long initial syllable before Proto-Bantu vowel length was lost.

The split in Nguni high-toned stems and the exceptions to local shift may now be understood as having arisen in the same way as has been argued for in Shambala, Qhalaxari, Digo, and Rimi. Notice, first, that the result of local spread in (62), above, gives us the identical representation which is postulated as underlying for short initial vowel verb stems like -bôna 'see' in Nguni. That is, the representation in (59b) could be derived by allowing Local Spread to apply regularly to stems derived from short initial vowel roots (note that final syllables would no longer be extratonal in this analysis). Neutralization of short initial vowel disyllabic stems (see (58), above) in Nguni would then be derived by the same two-step process found in ChiZigula, Digo, and Rimi: penult high tones shift to the final syllable and then are deleted by a rule of final high tone deletion. Local Shift would also apply regularly to trisyllabic stems derived from short initial vowel roots $(55 \mathrm{a}, \mathrm{c})$. In contrast, if historically long initial vowel roots were still bimoraic when Local Spread (15) applied to them, the result would be a level high tone on the initial syllable of disyllabic stems just like in the Shambala, Qhalaxari, and Rimi cognates in (63), (65), and (67B) above. The lack of shift in some trisyllabic noun stems can then be accounted for by positing that in all the 
Nguni languages underlyingly long initial vowels in noun stems remain bimoraic when roots have suffixes added to them. Local Spread again just applies from the first to the second mora of the initial syllable before the vowel is shortened, giving the appearance of lack of spread, as illustrated below:

(68) Derivation of (55g) ma-sélana 'small thieves'

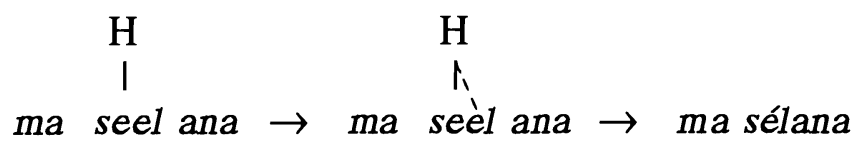

Trisyllabic verb stems also retain the tonal contrast between long and short initial vowel roots in Xhosa, but the contrast is neutralized in Zulu and Ndebele (see (55), above). To account for the Zulu and Ndebele verb data, the underlying long vowels in verb stems must be shortened when they are not in the penult syllable before Local Spread applies. In all other cases, long vowels are shortened only after Local Spread applies.

A complication with the analysis proposed here is that Leftbranch Delinking now does not apply to all multiply-linked high tones. Long initial vowel roots have a level high tone, not a rising contour as might be expected if delinking applied to them. Also, as mentioned above, the derivation of the falling contour in Zulu and Xhosa and the level high tone in Ndebele in some contexts on short initial vowel disyllabic stems depends on their not undergoing Leftbranch Delinking. Thus, Leftbranch Delinking must be constrained, first, from applying when both morae to which the high tone is linked are constituents of the same syllable:

(69) Constraint \#1 on Leftbranch Delinking

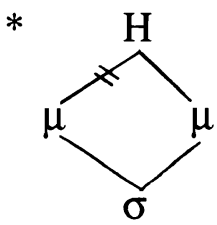

Leftbranch Delinking must also not apply (at least in Zulu-it does apply optionally in Ndebele) to a multiply-linked high tone whose rightmost branch is linked to the phrase-final syllable: 
(70) Constraint \#2 on Leftbranch Delinking (phrase-finally)

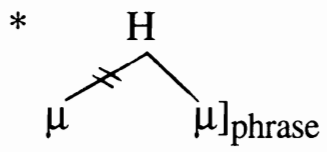

These conditions on delinking are admittedly complex, but they reflect a complex and evolving situation in Nguni. Only in Xhosa is the underlying vowel length contrast maintained consistently in trisyllabic stems. In Zululand Zulu and Xhosa the short initial vowel disyllabic stems are pronounced with a falling contour on the penult only in some conjugations, but in many others are pronounced with a level high tone in the penult just as the long initial vowel stems are. In Natal Zulu, it appears [J. Khumalo, personal communication] that the two-way split has disappeared entirely, so that disyllabic verb stems in all conjugations are realized with a level high tone, e.g. -bôna 'see' is pronounced -bóna). That is, the direction of change in Zulu and Xhosa is for all disyllabic stems to be acquiring the long initial vowel tone pattern. In Ndebele disyllabic high-toned stems also neutralized with the long initial vowel roots and are realized with a level high tone. But, according to Rycroft [1983], for younger speakers the disyllabic stems derived from short initial vowel roots are merging with toneless stems due to Final High Deletion (see (58), above). Derived trisyllabic Zulu and Ndebele verb stems all undergo shift, indicating that all stems are merging with the short initial vowel stems once the stem-initial long vowel is no longer in the penult.

This general tendency for disyllabic stems to acquire the long initial vowel tone pattern and for trisyllabic stems to acquire the short initial vowel pattern in the development of Nguni might be attributable to the fact that the only surface long vowels are in the penult [Doke 1926]. As in most Southern Bantu languages [Doke 1954], the penultimate syllable is lengthened in Nguni (most noticeably phrase-finally) due to regular stress on that syllable. As Dickens [1984] suggests for Qhalaxari (Sotho), another Southern Bantu language, this could have eventually caused the original underlying vowel length contrast to be neutralized on the surface, since both long initial vowel and short initial vowel disyllabic stems would have come to have a long vowel in the penult. Trisyllabic long initial vowel stems would have lost underlying vowel length on the unstressed antepenult, leading to the present surface pattern of non-contrastive, stress-induced vowel length only in the penult. It would then be a rather natural development for all disyllabic stems, with a stem-initial syllable in penult position, to acquire the long initial vowel tone pattern since this syllable would always have a lengthened vowel. For trisyllabic stems, on the other hand, the stem-initial syllable is in the antepenult, where surface long vowels do not occur. It would then also be a natural development for trisyllabic stems to come to have the short initial vowel tone pattern. 
One last question to be answered is why trisyllabic stems which are derived from monosyllabic (CV) stems (like (55e) n-twányana 'tiny thing') should fail to undergo local shift. An obvious solution is to posit that monosyllabic stems are also underlyingly bimoraic. This position does, in fact, have support from other Bantu languages. Hyman and Katamba [1990], for example, have argued that monosyllabic stems are bimoraic in LuGanda, and Hyman [personal communication] suggests that in Kinande (confirmed by Mutaka [personal communication]) and in Chaga evidence can also be found that monosyllabic stems are bimoraic. The derivation of the trisyllabic stems derived from monosyllabic stems given in (55e), above, would thus be parallel to that of (55g) given in (68).

The fact that some trisyllabic high stems undergo local shift while others do not is, then, fairly easily accounted for once we ascertain that the non-shifting stems historically (and, I posit, underlyingly) have long initial vowels, while the shifting stems have short initial vowels. The apparent exceptions to Local Spread among trisyllabic stems actually do undergo Local Spread from the first to the second mora of the underlyingly long initial syllable. Assuming that Local Spread applies at a point in the derivation when the underlying vowel length contrast still remains also accounts for the two-way split in Nguni high tone stems and for the fact that short initial vowel stems undergo Final High Deletion. All high-toned stems may have an unassociated high tone underlyingly, as in (59a), above, in this analysis, and none need to be lexically marked to undergo (or not undergo) Local Spread (or Accent Shift/Hop as in Peterson [1989b] or Goldsmith, Peterson, and Drogo [1986]), since this falls out from the underlying vowel length contrast. Finally, not only does this analysis provide a simple, general analysis for Nguni tone patterns, but it also shows that the apparently anomalous two-way split in the high-toned stems, (other) apparent exceptions to local tone spread/shift, and neutralization of (some) disyllabic stems in Nguni actually have clear parallels in other Bantu languages, where similar facts can be accounted for with very similar rules. These relationships were obscured, at best, in previous analyses.

3.3. Other exceptions. There is one class of exceptions to local shift within the (super-)stem in Zululand Zulu and Xhosa (the corresponding data were not available to me for Ndebele) which my analysis cannot account for. Claughton [1983] and Louw [1971] remark for Xhosa, and Khumalo [personal communication] has confirmed for Zulu, that the high tone on an OP fails to shift onto a disyllabic low stem in one context, namely, when the disyllabic stem may be analyzed as an extended (derived) monosyllabic stem. In (71b), below, for example, -wisa 'to drop' is transparently derived by adding the causative suffix, -isa, to the monosyllabic (CV) root, $-W(a)$ to fall' and (71c), -1wisa is the causative form of $-1 w$ (a) 'to fight.' Local Spread also fails to apply to high tones on object prefixes preceding the low CV stems themselves, as shown by (71a). (Remember that fi- 
nal syllables are not extratonal for Local Spread in this analysis.) High tones on object prefixes preceding trisyllabic stems derived from the low CV stems do undergo Metrical Spread, however, as shown in (71d):

(71) CV Low Stems + OP's showing no Local Spread (verbs have form: Inf.

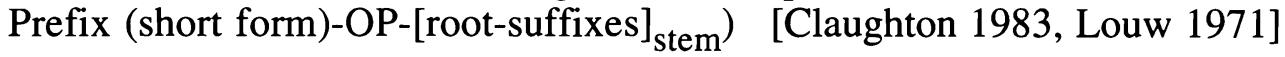
a. ku-yí-[1wa]
b. ku-yí-[w-isa]
c. ku-y!́-[1w-isa]
d. ku-yi-[1w-ísisa]

'to fight it'

'to drop it'

'to help fight it'

'to help fight it well'

Since there are only a handful of the low CV stems, they may be marked as exceptions to Local Spread in the lexicon. As is predicted if this is a lexical property, the verbs derived from the low CV stems $(71 b, c)$ retain this exceptionality marking.

For the sake of completeness, it is necessary to mention that there are a few other exceptions to local shift. For example, high tones linked to certain nominal agreement pre-prefixes do not undergo local shift, although they do undergo metrical shift, as illustrated below:

(72) Exceptions to Local Shift from nominal preprefixes
a. í-thanga
b. îi-zi-ngululé
but
c. $\underline{i}$ :-thang-ány-ana
d. $\underline{i}$-zi-tshúdeni

'pumpkin'

'leopards'

'tiny pumpkin'

'students'

The class agreement prefix in $(72 \mathrm{a}, \mathrm{c})$ is often transcribed with a long vowel, as I have done, so lack of apparent shift in that case may be accounted for in the same way as for the long initial vowel stems. I do not have an explanation for why Local Spread fails from the preprefix in cases like (72b), though. Finally, Local Spread does not apply outside the domain of the super-stem (OP + verb stem) in all verb conjugations, although it applies regularly to subject and object prefixes in the present indicative tense. Since these exceptions are all morphologically conditioned, Local Spread seems to be a lexical rule which applies within certain morphological domains. More research is necessary to determine exactly how the domain of local shift may best be defined. In any case, the fact that there is some evidence that Local Shift is a lexical rule, while Metrical Shift may be ar- 
gued to be a phrasal (post-lexical) rule (see $§ 1.4$., above) is a further argument that Local Shift must be ordered before Metrical Shift [Rubach 1984].

\section{Conclusion}

In sum, I have argued that Nguni has two tone shift rules: a local rule, which shifts a high tone one syllable to the right, and a metrical rule, which shifts a high tone to the antepenult after that syllable has been assigned metrical prominence. The local rule must apply before the metrical rule, because it may shift high tones which are originally associated with the antepenult to the penult, but it never applies to high tones associated with the antepenult by the metrical spread rule. One advantage of this analysis is that it unifies all the cases of antepenult to penult shift which were treated as separate sets of exceptions to antepenult shift by earlier analyses (Khumalo [1987], Goldsmith, Peterson, and Drogo [1986], Peterson [1989b]). Furthermore, the current two-way split in Nguni high-toned verb stems can be explained if we assume that Local Spread applies to the stems before they lose their underlying (and historically-motivated) vowel length contrast. The underlying vowel length contrast was also shown to account for many apparent exceptions to Local Spread.

Ordering a local tone rule before metrical rules, as in the present analysis, conflicts with a hypothesis (Goldsmith [1982] and Sietsema [1989]) which consigns metrical and non-metrical tonal rules to separate blocks in the grammar, with all metrical rules preceding all non-metrical tonal rules. However, I have argued that allowing non-metrical tone rules to precede metrical rules is not only necessary for Nguni but may be argued for in other Bantu languages, as well. To account for all these cases, our model of phonology must allow non-metrical rules to precede, and even feed, metrical rules in the grammar.

\section{REFERENCES}

Bunn, G. and R. Bunn. 1970. "Golin Phonology." Pacific Linguistics, Series A, 23:1-7.

Clark, Mary M. 1988. "An accentual analysis of the Zulu noun." In H. van der Hulst and N. Smith (eds.), Autosegmental Studies on Pitch Accent, pp. 51-79. Dordrecht: Foris. 
Claughton, John S. 1983. The Tones of Xhosa Inflections. Communication no. 13, Department of African Languages, Rhodes University, Grahamstown, S. A.

Cope, A. T. 1970. "Zulu tonal morphology." Journal of African Languages 9(3):111-152.

Dickens, P. 1984. "Qhalaxari verb tone classes.” African Studies 43:109-118.

Doke, C. M. 1926. "The phonetics of the Zulu language." Bantu Studies 2 (Special Number).

Doke, C. M. 1954. The Southern Bantu Languages. London: Oxford University Press for the International African Institute.

Downing, L. J. 1989. "The interaction of tone and intonation in Jita yes/no questions." In E.G. Bokamba (ed.), Proceedings of the 20th ACAL. Studies in the Linguistic Sciences 19(2):91-113.

Downing, L. J. 1990. "Problems in Jita tonology." Ph.D. dissertation, University of Illinois.

Goldsmith, J. 1982. "Accent systems." In H. van der Hulst and N. Smith (eds.), The Structure of Phonological Representations, Part 1, pp. 47-63. Dordrecht: Foris.

Goldsmith, J. 1984. "Meeussen's Rule." In M. Aronoff and R. T. Oehrle (eds.), Language Sound Structure, pp. 245-259. Cambridge, MA: The MIT Press.

Goldsmith, J. 1986. "Tone in the CiRuri present continuous." In K. Bogers, H. van der Hulst, and M. Mous (eds.), The Phonological Representation of Suprasegmentals, pp. 95-108. Dordrecht: Foris.

Goldsmith, J. 1987. "Tone and accent and getting the two together." Proceedings of the Berkeley Linguistics Society 13.

Goldsmith, J., K. Peterson, and J. Drogo. 1986. "Tone and accent in the Xhosa verbal system." ms., University of Chicago.

Greenberg, J. H. 1948. “The tonal system of Proto-Bantu." Word 4:196-208.

Halle, M. and J.-R. Vergnaud. 1987. An Essay on Stress. Cambridge, MA: The MIT Press. 
Hayes, B. 1980. "A metrical theory of stress rules." Ph.D. dissertation, Massachusetts Institute of Technology.

Hayes, B 1982. "Extrametricality and English stress." Linguistic Inquiry 13:227-276.

Hyman, L. and E. R. Byarushengo. 1984. "A model of Haya tonology." In G. N. Clements and J. Goldsmith (eds.), Autosegmental Studies in Bantu Tone, pp. 53-104. Dordrecht: Foris Publications.

Hyman, L. and R. G. Schuh. 1974. "Universals of tone rules: evidence from West Africa." Linguistic Inquiry 5:81-115.

Katamba, F. X. and L. Hyman. 1990. "Final vowel shortening in LuGanda." Studies in African Linguistics 21:1-59.

Kenstowicz, M. and C. Kisseberth. 1990. "Chizigula tonology-the word and beyond." In D. Zec and S. Inkelas (eds.), Proceedings of the Stanford Conference on the Syntax-Phonology Interface, pp. 163-194.

Khumalo, James S. M. 1987. "An autosegmental account of Zulu phonology.” $\mathrm{Ph} . \mathrm{D}$. dissertation, University of the Witwatersrand, R. S. A.

Kiparsky, P. 1985. "Some consequences of Lexical Phonology." Phonology Yearbook 2:83-136.

Kisseberth, C. W. 1984. "Digo tonology." In G. N. Clements and J. Goldsmith (eds.), Autosegmental Studies in Bantu Tone, pp. 105-182. Dordrecht: Foris Publications.

Kisseberth, C. W. and S. Mmusi. 1989. "The tonology of the object prefix in Setswana." Paper presented at the 20th Annual Conference on African Linguistics, University of Illinois at Urbana-Champaign.

Lanham, L. W. 1958. "The tonemes of Xhosa." African Studies 17(2):65-81.

Laughren, M. 1984. "Tone in Zulu nouns." In G. N. Clements and J. Goldsmith (eds.), Autosegmental Studies in Bantu Tone, pp. 183-234. Dordrecht: Foris Publications.

Leben, W. 1973. "Suprasegmental phonology." Ph.D. dissertation, Massachusetts Institute of Technology. [Published, New York: Garland, 1979.] 
Levergood, B. 1984. "Rule-governed vowel harmony and the strict cycle." NELS 14:275-293.

Lieber, R. 1987. An Integrated Theory of Autosegmental Processes. (SUNY Series in Linguistics.) Albany, NY: SUNY Press.

Louw, J. A. 1971. "The tonal paradigm of the verb in Xhosa." In V. Six et al (eds.), Afrikanische Sprachen und Kulturen: ein Querschnitt. Hamburger Beiträge zur Afrika-Kunde, 14. Hamburg: Deutsches Institut für Afrikaforschung.

Louw, J. A. 1983. "Some tone rules of Tsonga." Afrika und Übersee 46:13-24.

Meeussen, A. E. 1955. "Tonunterschiede als Reflexe von Quantitäts-unterschieden im Shambala." In J. Lukas (ed.), Afrikanistische Studien, pp. 154156. Berlin: Akademie Verlag.

Myers, S. P. 1987. "Tone and the structure of words in Shona." Ph.D. dissertation, University of Massachusetts-Amherst.

Nicholson, R. and R. Nicholson. 1962. "Fore phonemes and their interpretation." Oceania Linguistic Monographs No. 6, pp. 128-148. Studies in New Guinea Linguistics.

Nurse, D. 1979. "Description of sample Bantu languages of Tanzania." African Languages 5(1):iv-150.

Peterson, K. 1987. "Accent in the Chichewa verb." In A. Bosch, B. Need, and E. Schiller (eds.), 23rd Annual Regional Meeting of the Chicago Linguistics Society, Part 2: Parasession on Autosegmental and Metrical phonology, pp. 210-222. Chicago: Chicago Linguistics Society.

Peterson, K. 1989a. "Review of "Local and Metrical Tone Shift in Zulu and Xhosa'." Ms., University of Chicago.

Peterson, K. 1989b. "A comparative look at Nguni verbal tone." In I. Haik and L. Tuller (eds.), Current Approaches to African Linguistics, vol. 6, pp. 115137. Dordrecht: Foris Publications.

Pulleyblank, D. 1986. Tone in Lexical Phonology. Dordrecht: Reidel. 
Rubach, J. 1984. Cyclic and Lexical Phonology: The Structure of Polish. Dordrecht: Foris Publications.

Rycroft, D. K. 1963. "Tone in Zulu nouns.” African Language Studies 4:43-68.

Rycroft, D. K. 1979. “Tonal formulae for Nguni.” Limi 7:5-44.

Rycroft, D. K. 1980a. "Nguni tonal typology and Common Bantu." African Language Studies 17:33-76.

Rycroft, D. K. 1980b. "Ndebele and Zulu: some phonetic and tonal comparisons." Zambezia 7(2):109-128.

Rycroft, D. K. 1983. "Tone patterns in Zimbabwean Ndebele." Bulletin of the School of Oriental and African Studies 46(1):77-135.

Schadeberg, T. C. 1979. "Über die Töne der verbalen Formen im Rimi." Afrika und Übersee 42:288-313.

Sietsema, B. M. 1989. "Metrical Dependencies in Tone Assignment." Ph.D. dissertation, Massachusetts Institute of Technology.

Stevick, E. W. 1969. “Tone in Bantu.” IJAL 35(4):330-341.

Westphal, E. 1951. "The tone of verb stems in Xhosa." African Studies 10(3):107-112.

Westphal, E. and M. Notschweleka. 1967. Tonal Profiles of Xhosa Nominals and Verbo-Nominals. Communications from the School of African Studies, Series 32 . 
